\title{
Oxime-derived Palladacycles: Applications in Catalysis
}

\author{
Carmen Nájera, ${ }^{*[a]}$ \\ To Prof. Irina P. Beletskaya for her contribution to palladium chemistry
}

Abstract:

Phenone oxime-derived palladacycles are stable, easy to prepare and excellent source of three- and four-atom Pd clusters able to show excellent catalytic activity in most of the classical carbon-carbon bond forming reactions (Mizoroki-Heck, Matsuda-Heck, Suzuki-Miyaura, Stille, Kumada, Hiyama, Ullmann, Sonogashira and Glasser) in general with better performance than $\mathrm{Pd}(\mathrm{OAc})_{2}$ or other Pd salts. Aryl iodides, bromides, chlorides and imidazolyl sulfonates can be used as substrates not only in organic solvents but also in aqueous solvents including neat water. Appropriate general reaction conditions are found to perform efficiently these C-C bond forming reactions. They have been also used in carbonylations, several types of annulations, ketone arylations, C-H activation, oxime rearrangements and behave as metalloenzymes in hydrolytic processes among others. Not only dimer complexes can be used but also monomer ones with an additional ligand as well as supported on polymers, silica, and bearing ionic or fluorinated tags.

\section{Introduction}

Palladacycles ${ }^{[1-5]}$ are well-known organometallic compounds since 1965 when cyclopalladated azobenzene was synthesized by Cope $^{[6]}$ and were introduced as catalysts by Hermann-Beller in 1995. ${ }^{[7]}$ They constitute a big family of thermally stable $\mathrm{Pd}$ complexes in solid state. However, in solution can suffer decomposition generating $\mathrm{Pd}(0)$ complexes or nanoparticles (NPs). Oxime-derived 5-membered palladacycles are one example of this family, which were prepared in 1970 by ortho-palladation of oximes with alkali metal tetrachloropalladates in the presence of sodium acetate. ${ }^{[8]}$ They are very robust compounds and at the same time have shown excellent catalytic activity in many $\mathrm{C}-\mathrm{C}$ bond forming reactions ${ }^{[9-11]}$ but also in other processes. Different palladacycle dimers derived from aromatic 1-2 and aliphatic 3 ketone oximes have been prepared and used in catalytic processes (Figure 1). They can be easily prepared even by undergraduate students, some of them such as $1 \mathbf{d}$ and $\mathbf{1 e}$ are commercially available.

The formation of highly active zero-valent Pd species from different palladacycles has been well-stablished. ${ }^{[2]}$ In our initial experiments on Mizoroki-Heck $(\mathrm{M}-\mathrm{H})$ reaction with palladacycle 1d we observed a 20 min induction period and the insertion of the olefin, $n$-butyl acrylate, in the $\mathrm{Pd}-\mathrm{C}$ bond with subsequent formation of $\operatorname{Pd}(0)$ species. ${ }^{[12]}$ TEM analysis detected Pd NPs in the range 0.9-1.2 nm and some aggregates (see, Section 2.1). By using the Kaiser oxime resin 4 (Figure 1) either in $\mathrm{M}-\mathrm{H}^{[13]}$ or in Suzuki-Miyaura (S-M) ${ }^{[14]}$ reactions 3-10 nm sized Pd NPs were detected in solution (see, Sections 2.1 and 3.1). Moreover, after addition of $\mathrm{Hg}(0)$ these reactions stop to proceed.

Recently, Corma et al. ${ }^{[15]}$ have found that when different Pd sources such as $\mathrm{Pd}(\mathrm{OAc})_{2}, \mathrm{Pd} \mathrm{NPs}(3.9 \mathrm{~nm})$ in solution, $\mathrm{Pd}_{2} \mathrm{dba}_{3}$, SPhos- $\mathrm{Pd}(\mathrm{OAc})_{2}, \mathrm{Pd} / \mathrm{C}(1 \mathrm{wt} \%)$, and palladacycle $1 \mathrm{e}$ are used in the $\mathrm{M}-\mathrm{H}$ reaction in anhydrous media they start to decompose after few minutes to form 2-10 nm Pd NPs in agreement with findings from other groups. ${ }^{[16,17]}$ However, after two more additional hours these NPs were not the active catalytic species. Interestingly, the reaction started when the formation of three- and four-atom Pd clusters took place. Moreover, when water $(1 \% \mathrm{v} / \mathrm{v})$ was added at reaction time zero the induction period disappeared. This

[a] Prof. C. Nájera

Dpto. de Química Orgánica and Centro de Innovación en Química Avanzada (ORFEO-CINQA), University of Alicante

Apdo. 99, E-03080, Alicante, Spain

Fax: (+) 0034-965903549

E-mail: cnajera@ua.es 
observation supported that in the case of palladacycle $1 \mathrm{e}$ the ligand did not play any role and water promotes the formation of Pd clusters from every Pd source. These 3- and 4-atom Pd clusters are anionic in nature promoting efficiently the oxidative addition of aryl iodides and bromides for $\mathrm{M}-\mathrm{H}, \mathrm{S}-\mathrm{M}$, Stille and Sonogashira reactions. The formation of subnanometric Pd clusters by water is also promoted by amines and alcohols. ${ }^{[15]}$ This review deals with the catalytic applications of phenone oxime palladacycles in $\mathrm{C}-\mathrm{C}$ bond forming reactions and another processes.<smiles>[R]c1ccc2c([R])n(O)[R6](Cl)c2c1</smiles>

1a: $R^{1}=M e, R^{2}=H$

1b: $\mathrm{R}^{1}=\mathrm{Ph}, \mathrm{R}^{2}=\mathrm{H}$

1c: $\mathrm{R}^{1}=4-\mathrm{MeOC}_{6} \mathrm{H}_{4}, \mathrm{R}^{2}=\mathrm{OMe}$

1d: $\mathrm{R}^{1}=4-\mathrm{ClC}_{6} \mathrm{H}_{4}, \mathrm{R}^{2}=\mathrm{Cl}$

1e: $\mathrm{R}^{1}=\mathrm{Me}, \mathrm{R}^{2}=\mathrm{OH}$

1f: $\mathrm{R}^{1}=\mathrm{R}^{2}=\mathrm{H}$

1g: $\mathrm{R}^{1}=4-\mathrm{NO}_{2} \mathrm{C}_{6} \mathrm{H}_{4}, \mathrm{R}^{2}=\mathrm{H}$

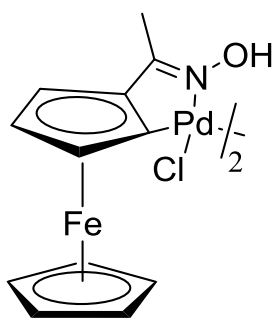

2<smiles></smiles>

3<smiles></smiles>

4<smiles></smiles>

5a: $\mathrm{R}=\mathrm{Me}$

5b: $\mathrm{R}=\mathrm{Ph}$

Figure 1.Oxime-derived palladacycles.

\section{Heck reactions}

\subsection{Mizoroki-Heck reaction}

Initial studies were performed with palladacycles $\mathbf{1}$ for the arylation of acrylates with aryl iodides in DMF at 110 ${ }^{\circ} \mathrm{C}$ in the presence of $\mathrm{Et}_{3} \mathrm{~N}$ with $0.01 \mathrm{~mol} \% \mathrm{Pd}$ and demonstrated that complex $1 \mathbf{d}$ was the most efficient 
palladacycle. ${ }^{[18]}$ At $160{ }^{\circ} \mathrm{C}$ it was possible to achieve $10^{8}$ TOF values. ${ }^{[19]}$ For the arylation with aryl bromides, $\mathrm{K}_{2} \mathrm{CO}_{3}$ as base, tetra- $n$-butylammonium bromide (TBAB) as additive $(20 \mathrm{~mol} \%)$ and $0.5 \mathrm{~mol} \%$ Pd loading at 130 ${ }^{\circ} \mathrm{C}$ were the best conditions. ${ }^{[19]}$ Only activated aryl chlorides reacted under the last reaction conditions. In the case of the arylation of styrenes, activated and deactivated aryl chlorides can be used at temperatures between $130^{\circ} \mathrm{C}$ to $160^{\circ} \mathrm{C}$. Palladacycle $\mathbf{1 d}$ has been used in the multiple vinylation of 1,2-dibromo and 1,3,5tribromobenzene with methyl acrylate ${ }^{[19]}$ and for polybromo-tribenzoquinacenes and -fenestrindanes ${ }^{[20]}$ with styrenes and methyl acrylate (Scheme 1). When these polyvinylations were performed with other Pd sources such as $\mathrm{Pd}(\mathrm{OAc})_{2}, \mathrm{PdCl}_{2}$, and $\mathrm{Pd}\left(\mathrm{PPh}_{3}\right)_{4}$ very poor results were observed. [20]<smiles>[R]C=CC(=O)OC(C)=O</smiles>

$(92 \%)$

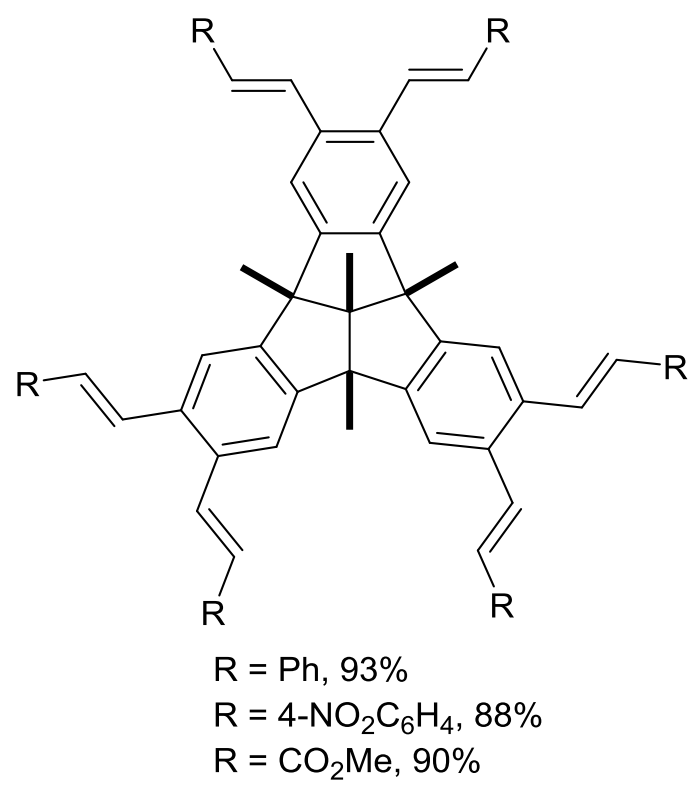

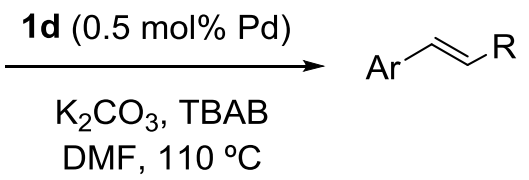<smiles>COC(C)=CC=Cc1cc(C=CC(C)=O)cc(C=CC(C)=O)c1</smiles>

$(99 \%)$<smiles>[R]C=Cc1cc2c(cc1/C=C/[R])C1c3cc(/C=C/[R])c(/C=C/[R])cc3C3c4cc(/C=C/[R])c(/C=C/[R])cc4C4c5cc(/C=C/[R])c(/C=C/[R])cc5C4C231</smiles>

Scheme 1. Vinylation of aryl bromides using palladacycle 1d.

Independently, lyer and Ramesh described the vinylation of aryl iodides, bromides and activated chlorides at 150 ${ }^{\circ} \mathrm{C}$ using palladacycles $\mathbf{1 b}$ and 1f. ${ }^{[21]}$ Similar results were found with the dimer ferrocenyl oxime palladacycle 2 and the monomeric complexes coordinated to triphenylphosphine or triethylphosphite. ${ }^{[22]}$ Saturated $\mathrm{N}$ heterocyclic carbene $(\mathrm{NHC})$ oxime palladacycle 5 , prepared by reaction of complexes 1 with the saturated $\mathrm{NHC}$ under $m$-xylene reflux, showed increasing thermal stability but similar efficiencies. ${ }^{[23-25]}$ Beletskaya et al. described the use of different NC-palladacycles including oxime-derivative 1a in $\mathrm{M}-\mathrm{H}$ reactions of iodobenzene with styrene and ethyl acrylate in $\mathrm{N}, \mathrm{N}$-dimethylacetamide (DMAc) at $85{ }^{\circ} \mathrm{C}$. ${ }^{[26]}$ The arylation of electron-rich styrenes such as 4-methoxy and 2,4-, 3-4, and 3,5-dimethoxystyrenes and 4-vinylpyridine has been performed with 4-hydroxyacetophenone palladacycle $1 \mathrm{e}$ and applied to the synthesis of methoxylated stilbenes, ${ }^{[27]}$ namely, stilbenoids derived from 3,5-dimethoxyiodobenzene, which have shown potent CYP1B1 inhibitory activity valuable for the development of chemo preventive or therapeutic cancer agents. ${ }^{[28]}$ Under the reaction conditions indicated in Scheme 2, methylated resveratrol $\left(\mathrm{Ar}=4-\mathrm{MeOC}_{6} \mathrm{H}_{4}\right)$, piceatannol $\left[\mathrm{Ar}=2,4-(\mathrm{MeO})_{2} \mathrm{C}_{6} \mathrm{H}_{3}\right]$ and pinosilvine $(\mathrm{Ar}=\mathrm{Ph})$ were prepared, whereas in the case of using $\mathrm{Pd}(\mathrm{OAc})_{2}$ the reaction failed. 
<smiles>COc1cc(I)cc(OC)c1</smiles><smiles>C=C[TeH2+]</smiles>

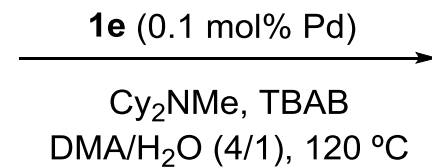<smiles>COc1cc(/C=C/Br)cc(OC)c1</smiles>

$(47-94 \%)$

Scheme 2. M-H reaction of 3,5-dimethoxyiodobenzene with styrenes.

$\mathrm{M}-\mathrm{H}$ reactions in water have been carried out with unsubstituted and $\beta$-substituted $\alpha, \beta$-unsaturated carbonyl compounds and aryl iodides in the presence of $\mathrm{Cy}_{2} \mathrm{NMe}$ as base at $120 \stackrel{\circ}{\circ}$. The monoarylation takes place with similar results with $0.1-0.01 \mathrm{~mol} \% \mathrm{Pd}$ loading either of $1 \mathrm{e}$ or $\mathrm{Pd}(\mathrm{OAc})_{2}$. In the case of aryl bromides aqueous DMA and TBAB (1 eq) as additive must be used and higher Pd loading (0.1-1 mol\%). ${ }^{[29,30]}$ The E-steroselectivity of the corresponding alkenes can be highly controlled with acrylic and crotonic derivatives. Increasing the amount of aryl iodide to 2 eq. and the Pd loading to $1 \mathrm{~mol} \%$, acrylic derivatives can be $\beta, \beta$-diarylated in water (Scheme 3). However, $\mathrm{Pd}(\mathrm{OAc})_{2}$ failed or gave very poor conversions. For the arylation of $\alpha, \beta$-unsaturated carbonyl compounds with aryl bromides aqueous DMA and TBAB as additive should be employed.

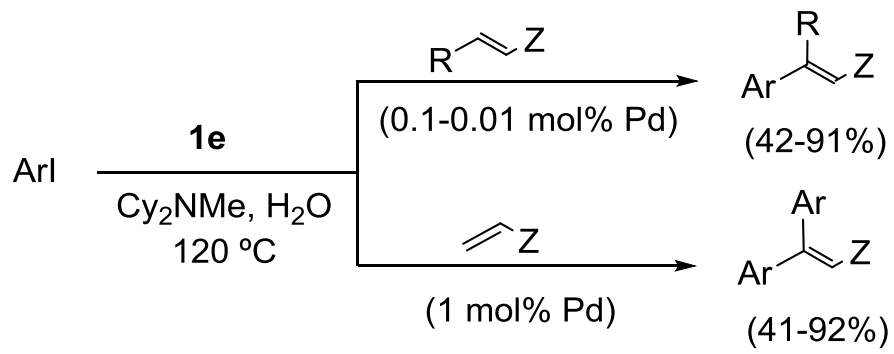

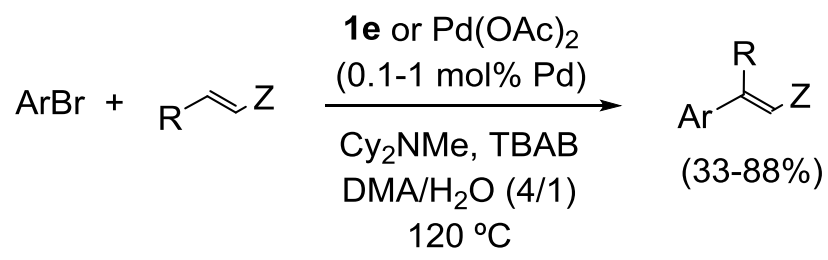

$$
\begin{aligned}
& {\left[\begin{array}{l}
\mathrm{R}=\mathrm{H}, \mathrm{Me}, \mathrm{Ph} \\
\mathrm{Z}=\mathrm{CO}_{2} \mathrm{Bu}^{\mathrm{t}}, \mathrm{COMe}, \mathrm{CN}, \mathrm{CONMe}_{2}
\end{array}\right]}
\end{aligned}
$$

Scheme 3. Mono- and di-arylation of acrylic derivatives.

The first immobilization of oxime-derived palladacycles was performed with the 4-hydroxyacetophenone derivative 1e, which was covalently anchored to different inorganic and organic supports. The mercaptopropyl functionalized silica 7a (Figure 2) was employed first in S-M reaction in water (see, Section 3.1). ${ }^{[31]}$ For the $\mathrm{M}-\mathrm{H}$ reaction an imidazolium group was anchored into $\mathbf{1 e}$ to give complex 8 (Figure 2). ${ }^{[32]}$ This palladacycle 8 is soluble in 1-butyl-3-methylimidazolium hexafluorophosphate and not extractable with ether giving very low yields when styrene was allowed to react with 4-bromoacetophenone (26\% yield) or with iodobenzene $(17 \%$ yield). However, the cyclopalladated Kaiser oxime resin 4 (cross-linked polystyrene, $1 \%$ divinylbenzene with $1.1 \mathrm{mmol} / \mathrm{g}$ oxime loading) containing $0.12 \mathrm{mmol} / \mathrm{g} \mathrm{Pd}$ was an efficient precatalyst in the $\mathrm{M}-\mathrm{H}$ reaction. ${ }^{[13,33]}$ Thus, for the arylation of acrylic and styrene derivatives with aryl iodides either in DMF at $110{ }^{\circ} \mathrm{C}$ or in $\mathrm{H}_{2} \mathrm{O}$ at $120 \stackrel{\circ}{\circ}$ using $\mathrm{Cy}_{2} \mathrm{NMe}$ as base, excellent yields were obtained with $0.0001-1 \mathrm{~mol} \% \mathrm{Pd}$ loading but in longer reaction times than with complexes 1d,e,g. At least during 8 cycles the catalytic activity was maintained during the recycling experiments, with better yields in $\mathrm{H}_{2} \mathrm{O}$ than in DMF and with $0.4-5 \% \mathrm{Pd}$ leaching levels in the product in DMF and $2-2.7 \%$ in $\mathrm{H}_{2} \mathrm{O}$ (determined by ICP-OES analyses). XPS analysis of the starting and recycled 4 showed the content of exclusively $\mathrm{Pd}(\mathrm{II})$ and poisoning experiments with $\mathrm{Hg}(0)$ stopped the reaction indicating that this supported palladacycle acts as source of $\mathrm{Pd}(0)$ clusters. ${ }^{[15]}$ For aryl bromides higher Pd loading and addition of TBAB in aqueous DMF must be used. 
<smiles></smiles>

$7 a$<smiles></smiles>

$7 b$<smiles></smiles><smiles></smiles>

8<smiles></smiles>

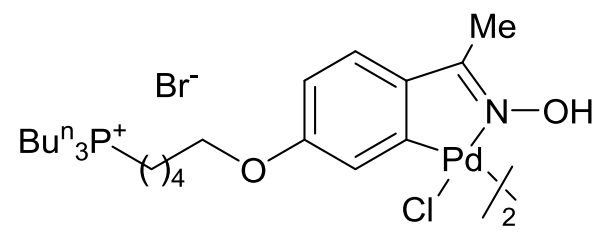

10

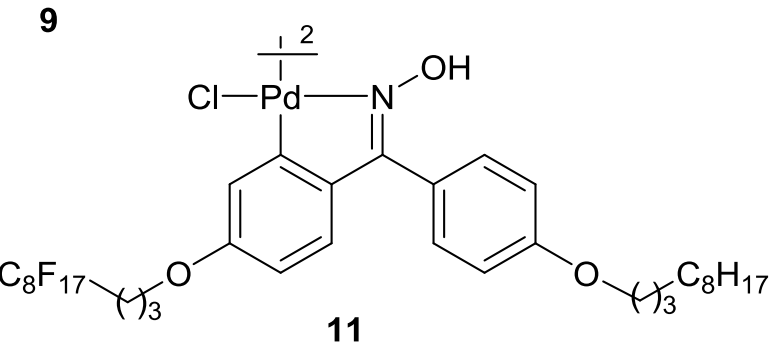

Figure 2. Supported oxime-derived palladacycles 7-11.

Coordinative immobilization of palladacyle 1a to poly(vinylpyridine)/glass composite materials shaped as Rasching rings or placed within the PASSflow ${ }^{\top \mathrm{M}}$ microreactor has been studied by Kirschning et al. ${ }^{[34]}$ This supported palladacycle 9 (Figure 2) has been used in M-H and S-M reactions in continuous flow mode. Under batch conditions good yields were obtained for the arylation of acrylates and styrenes with aryl iodides and bromides with $1 \mathrm{~mol} \% \mathrm{Pd}$ loading in $\mathrm{DMF}$ and $\mathrm{Et}_{3} \mathrm{~N}$ as base at $110{ }^{\circ} \mathrm{C}$ and $150 \stackrel{\circ}{\circ}$, respectively. However, under continuous flow conditions at $120{ }^{\circ} \mathrm{C}$ with $n-\mathrm{Bu}_{3} \mathrm{~N}$ as base at $120 \stackrel{\circ}{\circ}$ only aryl iodides gave satisfactory results. The Pd leaching was detected by using thiol- and pyridine-based scavengers and has been demonstrated that the poly(vinylpyridine) carrier has scavenging properties for $\mathrm{Pd}(0) \mathrm{NPs}$. 
Another example of an ionophilic palladacycle $\mathbf{1 0}^{[35]}$ (Figure 2) bears a phosphonium group covalently attached through a chain to complex $\mathbf{1 e}$, which has been used in an ionic liquid reaction medium giving better results than the imidazolium derivative 8 . The corresponding $\mathrm{M}-\mathrm{H}$ products were isolated by sublimation and the remaining ionic liquid-palladacycle mixture was recycled and reused.

As previously mentioned, electron-rich alkenes such as styrenes with electron-donating groups at the aromatic ring are more challenging substrates than acrylic derivatives for $\mathrm{M}-\mathrm{H}$ reactions. Acrolein diethyl acetal has been used instead of acrolein in order to avoid polymerization and accessibility problems. However, this three carbon atoms homologating agent by arylation under $\mathrm{H}-\mathrm{M}$ reaction conditions gave mixtures of cinnamaldehyde acetals and 3-arylpropanoate ethyl esters due to the two possible palladium hydride $\beta$-elimination from the palladated intermediate in the last step (Scheme 4). ${ }^{[36]}$ Cacchi et al. established the adequate reaction conditions for the chemoselective arylation of acrolein diethyl acetal. ${ }^{[3]}$ Cinnamaldehyde derivatives, which are important chemicals not only in food and cosmetic industries, but also due to their broad biological activity and their use as starting compounds in the preparation of non-linear optics, ${ }^{[38]}$ were prepared by using $\mathrm{Pd}(\mathrm{OAc})_{2}(3 \mathrm{~mol} \%)$, TBAA, $\mathrm{K}_{2} \mathrm{CO}_{3}, \mathrm{KCl}$ in DMF at $90{ }^{\circ} \mathrm{C}$ for aryl iodides and bromides. Whereas, for ethyl 3-arylpropanoates TBAC was used as additive and $n-\mathrm{Bu}_{3} \mathrm{~N}$ as base. ${ }^{[37]}$

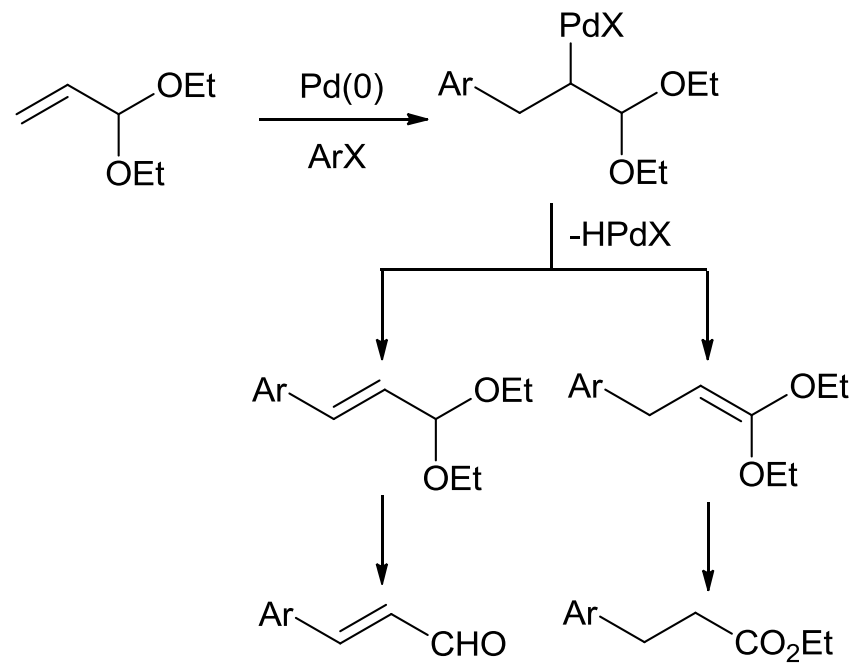

Scheme 4. Chemoselective arylation of acrolein diethyl acetal.

Aryl iodides, bromides and activated chlorides can be used for the synthesis of cinnamaldehydes using $1 \mathrm{~mol} \%$ of $1 \mathrm{e}$ (Figure 1) at $120{ }^{\circ} \mathrm{C}$ in DMA (Scheme 5). ${ }^{[39]}$ For the synthesis of ethyl $\beta$-arylpropionates dicyclohexylmethylamine was the adequate base facilitating the removal of $\mathrm{HX}$ in aqueous $\mathrm{DMA}$ at $90{ }^{\circ} \mathrm{C}$ for aryl iodides. For aryl bromides TBAB must be added and the temperature should be increased to $120{ }^{\circ} \mathrm{C}$ (Scheme 5). ${ }^{[38]}$ The Kaiser oxime resin derived palladacycle 4 (Figure 1) acted as well as Pd source for the synthesis of ethyl $\beta$-arylpropionates employing $0.1 \mathrm{~mol} \%$ of $\mathrm{Pd}$ loading being recycled during five runs with $0.06-0.008 \mathrm{ppm}$ $\mathrm{Pd}$ leaching in the solution. ${ }^{[40]}$ In the case of the synthesis of 2-(1-naphthyl)cinammaldehyde using 1bromonaphthalene the catalytic activity of $\mathbf{4}$ was maintained during four cycles with higher $0.8 \mathrm{ppm}$ Pd leaching in the solution. ${ }^{[40]}$ These reaction conditions have been used by Lo, Lam et al. using the fluorous oxime palladacycle 11 ${ }^{[41]}$ (Figure 2) under MW irradiation with only $0.023-0.076 \mathrm{ppm}$ Pd leaching during 5 runs in the case of 4-chlorocinnamaldehyde synthesis with moderate recovery of the catalyst $(63-84 \%){ }^{[42]}$

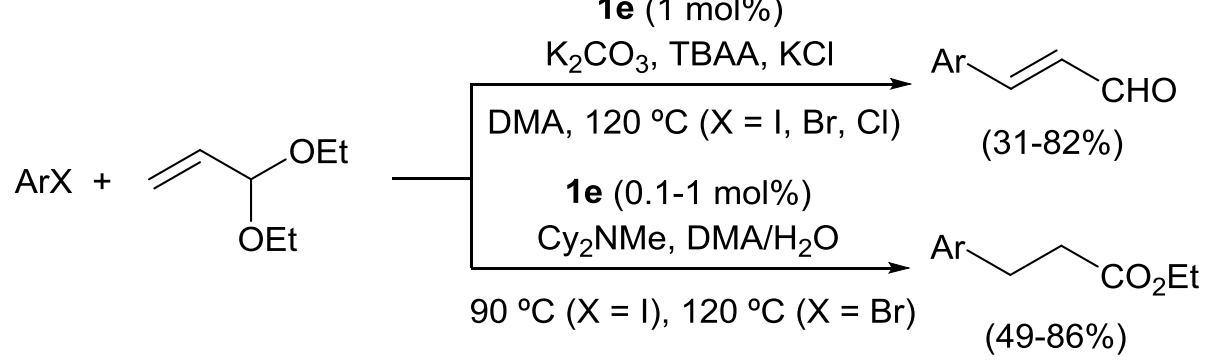

Scheme 5. Arylation of acrolein diethyl acetal catalyzed by $\mathbf{1 e}$. 
Allylic alcohols are non-activated alkenes for the $\mathrm{M}-\mathrm{H}$ reaction. They present regio- and chemoselectivity problems affording $\beta$ - and $\gamma$-arylated carbonyl compounds and/or allylic alcohols (Scheme 6). ${ }^{[43]}$ It has been proposed that the $\beta$-arylation takes place by a cationic pathway and the $\gamma$-arylation via a neutral mechanism. ${ }^{[44-47]}$

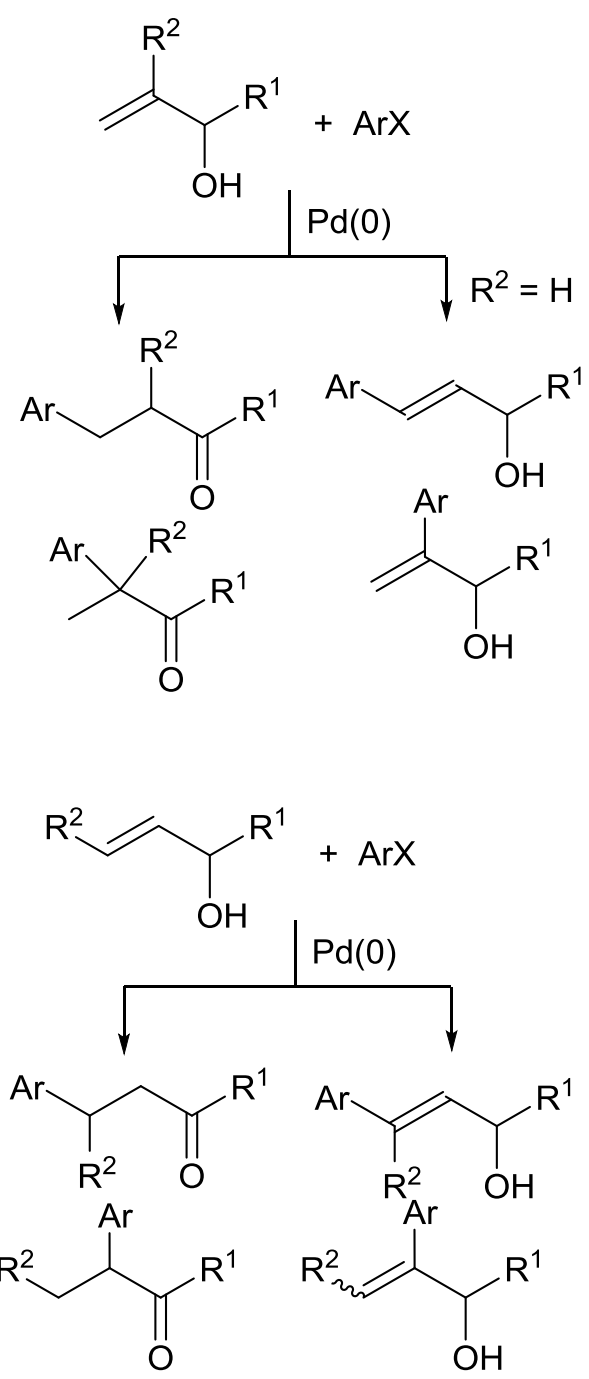

Scheme 6. M-H reaction with allylic alcohols.

By using dimer $1 \mathrm{e}$ or supported 4 complexes $(0.1-1 \mathrm{~mol} \% \mathrm{Pd})$, dicyclohexylmethylamine as base and TBAB as additive, in water for aryl iodides (54-85\%) and in aqueous DMA for aryl bromides (33-82\%), $\gamma$-arylation occurred according to the aforementioned mechanism, giving the corresponding $\beta$-arylated aldehydes and ketones in a highly regio- and chemoselective manner. ${ }^{[48]}$ However, when $\mathrm{Pd}(\mathrm{OAc})_{2}$ was used as catalyst much lower yields were obtained than with palladacycles. Representative examples are the synthesis of the anti-inflammatory drug nabumetone and the fragrance $\beta$-lilial (Scheme 7). Recycling experiments with the polymer complex 4 were performed at $80 \stackrel{\circ}{\circ}$ in water during at least 6 cycles for the arylation of but-3-en-1-ol with iodobenzene. 


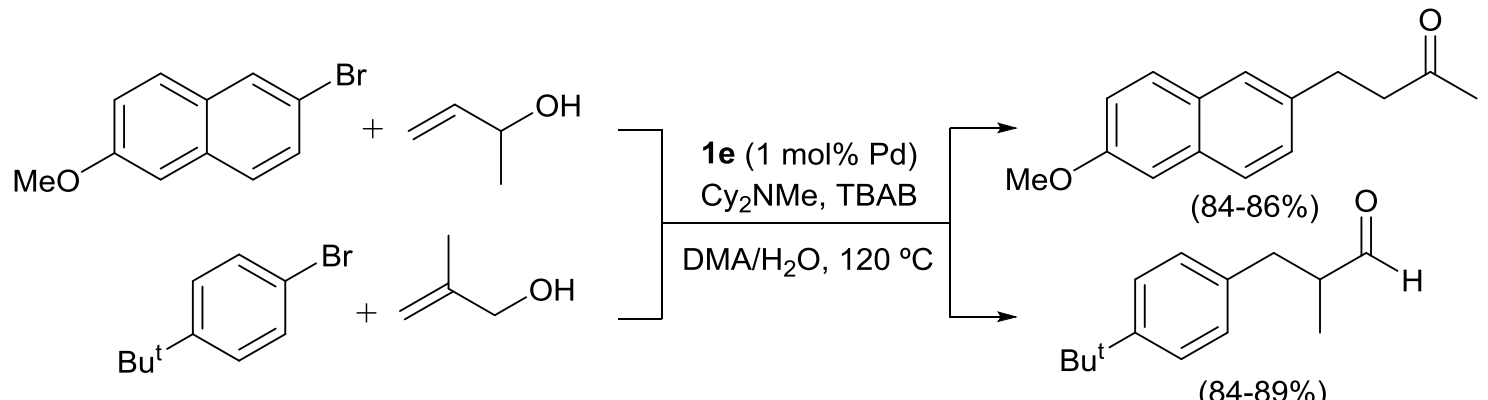

$(84-89 \%)$

Scheme 7. Synthesis of nabumetone and $\beta$-lilial.

The Mizoroki-Heck reaction of $N$-vinylphthalimide also presents problems of $\alpha$ - and $\beta$-arylation. ${ }^{[49]}$ Important compounds are $\beta$-arylated $N$-vinylphthalimides due to their biological activity and as non-linear optics, as well as starting compounds for the synthesis of phenethylamines. By using palladacycles 1e and 4 (Figure 1) (0.1-1 mol\%) was possible to perform regio- and diastereoselectively the $\beta$-arylation of $N$-vinylphthalimide in DMF with aryl iodides, bromides and chlorides in the presence of $\mathrm{Cy}_{2} \mathrm{NMe}$ as base and TBAB as additive at $120{ }^{\circ} \mathrm{C}$ under conventional or MW irradiation (Scheme 8). ${ }^{[50]}$ After hydrogenation of the styrylphthalimide $[\mathrm{Ar}=3,4,5$ $(\mathrm{MeO})_{3} \mathrm{C}_{6} \mathrm{H}_{2}$ ] with Wilkinson catalyst followed by hydrazinolysis, mescaline could be obtained in $56 \%$ overall yield. Recycling experiments in the case of complex 4 for the arylation with 4-bromoacetophenone allowed to reuse it during 4 cycles with 1.06-1.68 ppm Pd leaching. In the case of the fluorous oxime palladacycle 11 (Figure 2) $(0.5 \mathrm{~mol} \% \mathrm{Pd})$ aryl iodides and activated bromides and chlorides have been used working at 140 or $170 \stackrel{\circ}{\circ}$ under MW irradiation. ${ }^{[42]}$ Recycling experiments were performed with iodobenzene being active during 4 cycles with similar Pd leaching.

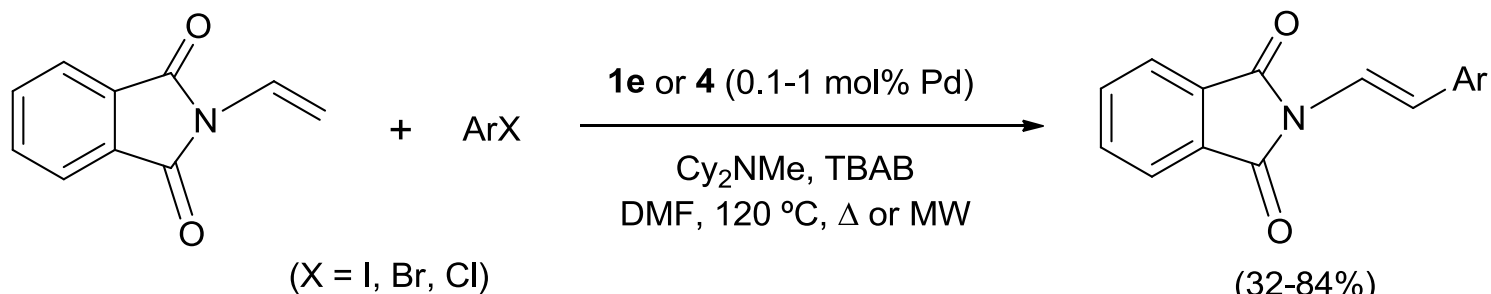

Scheme 8. M-H Reaction of $N$-vinylphthalimide.

Morita-Baylis-Hillman (M-B-H) adducts derived from acrylates and aldehydes have been arylated using palladacycle $1 \mathbf{d}(0.5 \mathrm{~mol} \% \mathrm{Pd})$ with aryl iodides in DMF as solvent and triethylamine as base at $110{ }^{\circ} \mathrm{C}$ providing $\alpha$-benzyl- $\beta$-keto esters in good yields by the group of Coelho (Scheme 9 ). ${ }^{[51,52]}$ Under the same reaction conditions a methylene pyrrolizidinone, prepared from the corresponding $\mathrm{M}-\mathrm{B}-\mathrm{H}$ adduct has been stereoselectively arylated, without isomerization to the corresponding cyclopentadione, to give precursors of pyrrolizidines, which are potential LFA-1 inhibitor agents (Scheme 9). ${ }^{[53]}$<smiles></smiles><smiles>[R]OC(=O)C(C[Al])C([R])=O</smiles><smiles>O=C1C(=[18O])[C@H](O)[C@H]2C[C@@H](O)CN12</smiles>

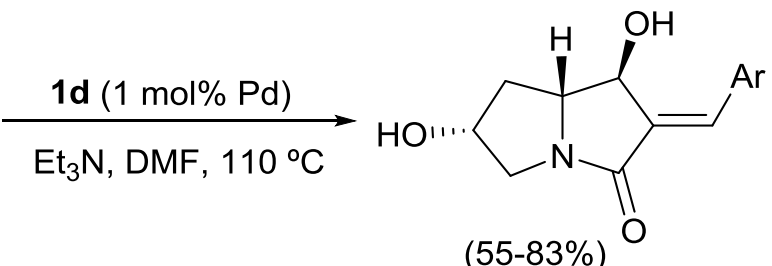<smiles>[18OH][18Os]</smiles>

$(55-83 \%)$ 
Scheme 9. Arylations of Morita-Baylis-Hillman adducts and a methylene pyrrolizidinone.

The arylation of ethylene is a rather challenging $\mathrm{M}-\mathrm{H}$ process which needs high pressures. ${ }^{[54]}$ However, by using the palladacycle derived from acetophenone oxime 1a (Figure 1) (3-5 mol\%), KOAc, phenothiazine (PTZ) as radical inhibitor and DMA as solvent, ethylene reacts with activated and deactivated aryl iodides and bromides at $105{ }^{\circ} \mathrm{C}$ providing styrenes in good to excellent yields with just an ethylene balloon (Scheme 10). ${ }^{[55]}$ Vinyl bromides have been used under the same reaction conditions to afford 1,3-dienes in good yields.

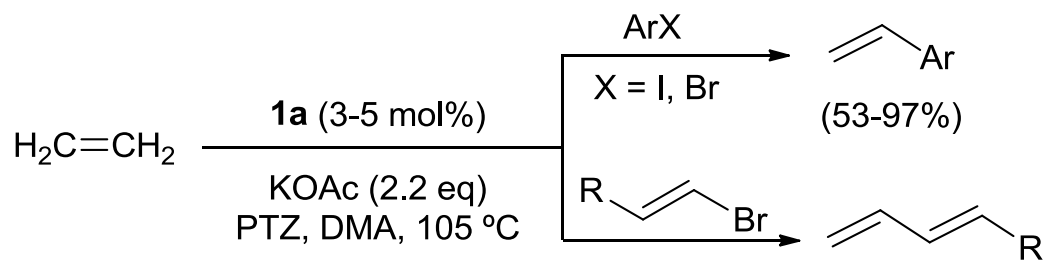

$(48-74 \%)$

Scheme 10. Arylation and vinylation of ethylene.

A highly stereo-controlled protocol to prepare 5-arylpipecolic acids and piperidine derivatives is based on an Rhcatalyzed cyclohydrocarbonylation of homoallylamines. These intermediate homoallylamines have been prepared by $\mathrm{M}-\mathrm{H}$ reaction with aryl iodides and different sources of $\mathrm{Pd}$, such as $\mathrm{Pd}(\mathrm{OAc})_{2}, \mathrm{Pd}\left(\mathrm{PPh}_{3}\right)_{4}$ or acetophenone oxime palladacycle 1a (Scheme 11). The later gave the best results using $0.01 \mathrm{~mol} \%$ of $1 \mathrm{a}, \mathrm{Et}_{3} \mathrm{~N}$ as base in DMF under MW irradiation at $120 \stackrel{\circ}{\mathrm{C}}$ for $20 \mathrm{~min}$, giving the arylated products in moderate to high diastereoselectivity. ${ }^{[56]}$<smiles>[R2]C(C=C)C([R2])N[C@H]1c2ccccc2C[C@H]1O</smiles><smiles>[R2]C(/C=C/[AlH2])[C@@H]([R2])N[C@H]1c2ccccc2C[C@H]1O</smiles>

$(50-68 \%)$

dr: $78 / 22-98 / 2$

Scheme 11. Arylation of homoallylamines.

\subsection{Heck-Matsuda reaction}

In 1977 Kikukawa and Matsuda described the arylation of alkenes with arenediazonium salts catalyzed by Pd as an efficient reaction. ${ }^{[57]}$ This process called Heck-Matsuda reaction $(\mathrm{H}-\mathrm{M})$ has been less studied than the $\mathrm{M}-\mathrm{H}$ reaction although a great variety of arenediazonium salts are commercially available or can be easily prepared from anilines. In addition, its reactivity is higher than aryl halides and triflates and does not required the use of phosphanes and bases. ${ }^{[58-60]}$ The arylation of electron-rich and electron-poor alkenes with an arenediazonium tetrafluoroborate bearing a fluorinated octyl-ponytail has been performed either using $\mathrm{Pd}(\mathrm{OAc})_{2}$ or 4hydroxyacetophenone oxime palladacycle $1 \mathrm{e}$ as source of $\mathrm{Pd}(1 \mathrm{~mol} \%)$ at room temperature in methanol. ${ }^{[61]} \mathrm{By}$ using ESI-MS experiments it could be found that the $\mathrm{Pd}(\mathrm{IV})$ species detected in the case of palladacycle 1e do not seem to act as intermediates of the reaction. TEM analyses of the reaction solution showed the formation of $\mathrm{Pd}$ NPs with both precatalysts. Ethyl vinyl ketone, acrylates, ethyl crotonate, styrenes and cyclopentene react in $\mathrm{MeOH}$ at room temperature in general in short reaction times (Scheme 12, Eq a). 


$$
\begin{aligned}
& \mathrm{Z}_{\mathrm{MeOH}, \mathrm{rt}} \mathrm{N}_{\mathrm{F}_{17} \mathrm{C}_{8}} \mathrm{TFA}^{-} \\
& \gamma_{Z}+\operatorname{ArN}_{2}{ }^{+} \mathrm{BF}_{4}{ }^{-} \stackrel{\mathrm{Pd}(\mathrm{OAc})_{2} \text { or } 1 \mathbf{e}(1 \mathrm{~mol} \% \mathrm{Pd})}{\mathrm{H}_{2} \mathrm{O}, \mathrm{rt}} \mathrm{Ar}_{Z} \\
& \text { [ } \left.\mathrm{Z}=\mathrm{CO}_{2} \mathrm{R}, \mathrm{COEt}, \mathrm{Ar}^{\prime}, \mathrm{CH}_{2} \mathrm{OAc}, \mathrm{CH}(\mathrm{OH}) \mathrm{CH}_{3}\right]
\end{aligned}
$$

Scheme 12. Arylation of alkenes with arenediazonium salts.

The H-M reaction can also be performed in water as solvent with different substituted arenediazonium tetrafluoroborates. ${ }^{[62]}$ Acrylic derivatives, styrenes, allyl acetate and but-3-en-2-ol have been used as alkenes giving the arylated products in moderate to high yields (Scheme 12, Eq b).

\section{Cross-coupling reactions}

\subsection{Suzuki-Miyaura reaction}

At the same time that the $\mathrm{M}-\mathrm{H}$ reaction using oxime-derived palladacycles was being studied, the SuzukiMiyaura (S-M) reaction was also considered. ${ }^{[18]}$ From the catalyst studies in toluene as organic solvent, the best results were obtained with $\mathbf{1 d}$ (Figure 1) at $110 \stackrel{\circ}{\circ} \mathrm{C}$ and with $\mathrm{K}_{2} \mathrm{CO}_{3}$ as base, whereas $\mathrm{Li}_{2} \mathrm{PdCl}_{4}$ gave poor yields. ${ }^{[63]}$ These reaction conditions were applied to the cross-coupling of arylboronic acids and aryl bromides with 0.01 to $0.001 \mathrm{~mol} \% \mathrm{Pd}$ loadings. However, for the cross-coupling of activated aryl chlorides aqueous DMF, TBAB (20 mol\%) as additive, $0.1 \mathrm{~mol} \%$ Pd loading at $130 \stackrel{\circ}{\circ} \mathrm{C}$ are employed as reaction conditions (Scheme 13). Methallyl chloride and 1-chloromethylnaphthalene react with arylboronic acids under the last reaction conditions giving diarylmethanes in good yields. These reaction conditions have also been applied to the synthesis of 4biarylacetic acids starting from 4-bromobenzyl p-tolyl sulfone. ${ }^{[64]}$

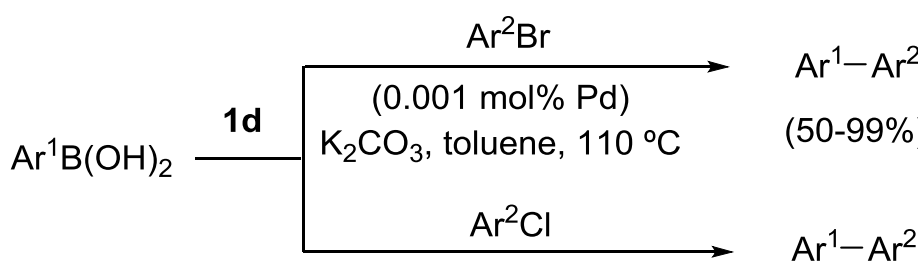

$$
\begin{aligned}
& \text { (0.1 mol\% Pd) } \\
& \mathrm{K}_{2} \mathrm{CO}_{3}, \mathrm{TBAB} \text {, } \\
& \mathrm{DMF} / \mathrm{H}_{2} \mathrm{O}(95 / 5), 130^{\circ} \mathrm{C}
\end{aligned}
$$

Scheme 13. S-M Reaction in organic solvents.

The 4-hydroxyacetophenone oxime palladacycle 1e (Figure 1) was prepared specifically for the S-M reaction in water. ${ }^{[65]}$ When the standard S-M reaction between phenylboronic acid and 4-chloroacetophenone was performed under water reflux with $\mathrm{K}_{2} \mathrm{CO}_{3}$ as base and TBAB (20 mol\%) as additive, 1 e gave better results than 1a with only 0.01 mol\% $\mathrm{Pd}$ loading. Under these reactions conditions $\mathrm{Pd}(\mathrm{OAc})_{2}$ gave only $10 \%$ yield and $\mathrm{Li}_{2} \mathrm{PdCl}_{4}$ failed. The scope of the reaction was studied with different activated and deactivated aryl and heteraryl chlorides with 0.01 to $1 \mathrm{~mol} \% \mathrm{Pd}$ loadings (Scheme 14). Aryl bromides gave biphenyls in refluxing water with high TONs (up to $10^{5}$ ) and TOFs (up to $5 \times 10^{4} \mathrm{~h}^{-1}$ ). ${ }^{[6]}$ Alternatively, for cross-couplings at room temperature of aryl bromides aqueous methanol and $\mathrm{KOH}$ as base can be used with TON up to $10^{4}$ and TOF up to $2 \times 10^{3} \mathrm{~h}^{-1}$ (Scheme 14). Comparative studies for the reaction of phenylboronic acid with 4-bromoacetophenone using $\mathrm{Pd}(\mathrm{OAc})_{2}$ or $\mathrm{Li}_{2} \mathrm{PdCl}_{4}$ at $\mathrm{rt}$ gave $50 \%$ and $48 \%$ yield, whereas $1 \mathrm{e}$ gave quantitative yields. This palladacycle showed high 
catalytic activity for the in situ S-M reaction of 4-chloroacetophenone and phenylboronic acid with $0.05 \mathrm{~mol} \% \mathrm{Pd}$ loading in $1 \mathrm{~h}$ intervals during two cycles (99\%) and decrease in the third and fourth run to $75 \%$ and $46 \%$, respectively. In the case of 4-bromoacetophenone $1 \mathrm{e}(0.001 \mathrm{~mol} \% \mathrm{Pd})$ showed a high efficiency using aqueous methanol and $\mathrm{KOH}$ as base at $60 \stackrel{\circ}{\mathrm{C}}$ during 5 cycles affording 4 -acetylbiphenyl in $>95 \%$ yield. ${ }^{[66]}$

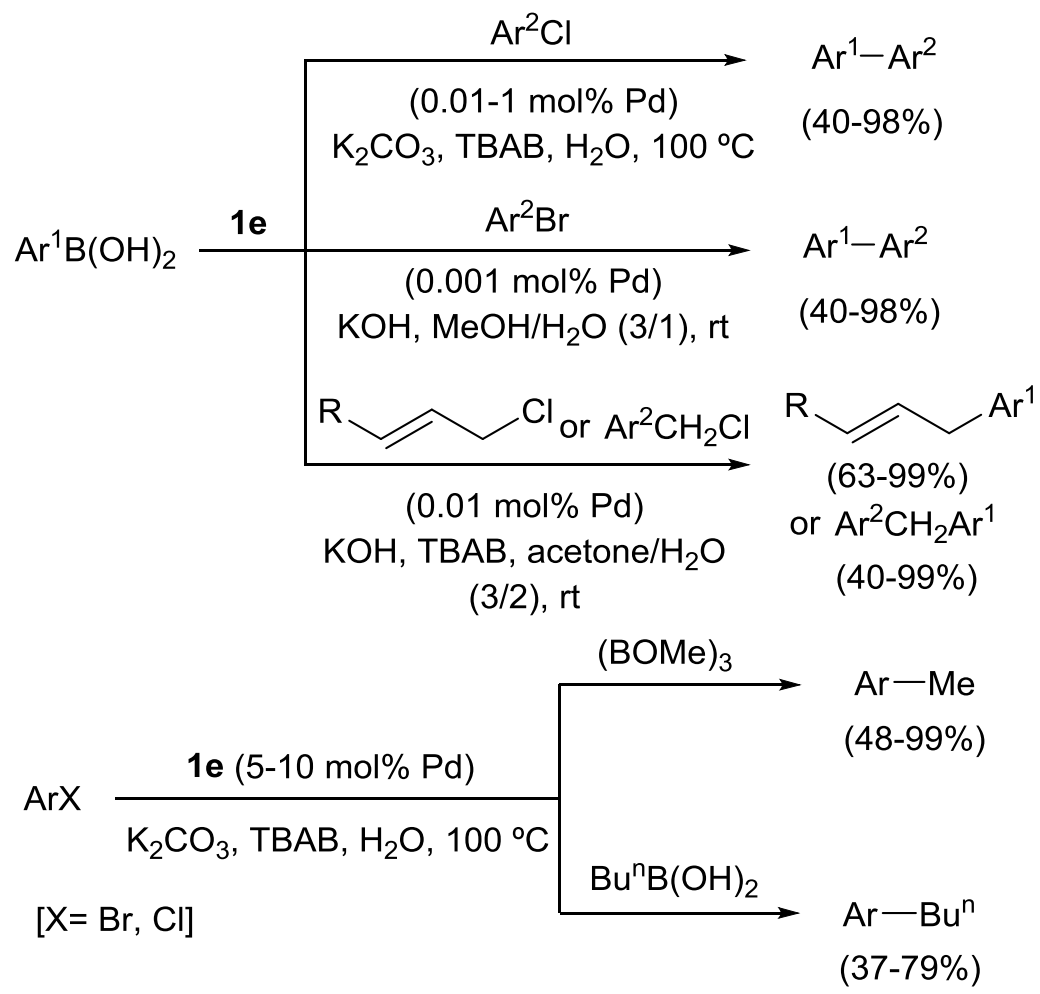

Scheme 14. S-M Reaction in water and aqueous solvents.

Trimethylboroxine and $n$-butylboronic acid are able to react with aryl bromides and activated aryl chlorides under water reflux with higher 5-10 mol\% Pd loadings. Cross-coupling reactions allowing the formation of $\mathrm{Csp}^{3}-\mathrm{Csp}^{2}$ bonds has been performed with cyclopentylmethylboronic acid and aryl bromides using $1 \mathrm{e}(1 \mathrm{~mol} \%)$ under water reflux and $\mathrm{K}_{2} \mathrm{CO}_{3}$ as base giving the corresponding products in 23-51\% yield. ${ }^{[6]}$ On the other hand $\mathrm{Csp}^{2}-\mathrm{Csp}^{3}$ bond forming reactions could also be performed efficiently with allyl and benzyl chlorides at rt with $\mathrm{KOH}$ as base, TBAB as additive in aqueous acetone (Scheme 14). ${ }^{[65,66]}$

Some selected applications of S-M in water are: a) the synthesis of the anti-inflammatory 4-biphenylacetic acid (felbinac) starting from 4-bromophenylacetic acid in 79\% yield (2 h, rt, 870 TON) or from 4-chlorophenylacetic acid in $50 \%$ yield ( $\left.25 \mathrm{~h}, 100{ }^{\circ} \mathrm{C}, 50 \mathrm{TON}\right)$; b) the analgesic 4-phenylmandelic acid was obtained from 4bromomandelic acid in $87 \%$ yield ( $2 \mathrm{~h}, \mathrm{rt}, 870 \mathrm{TON})$ and from the chloro-derivative in $42 \%$ yield $\left(2.5 \mathrm{~h}, 100{ }^{\circ} \mathrm{C}, 42\right.$ TON); c) 4'-methylbiphenyl-2-carbonitrile, an intermediate for the synthesis of the antihypertensive 'sartan' family drugs, has been prepared from 2-chlorobenzonitrile and 4-methylphenylboronic acid in $70 \%$ yield $\left(2 \mathrm{~h}, 100{ }^{\circ} \mathrm{C}\right.$, $70 \mathrm{TON})$; d) 4,5-diphenyl-2-methyl-3-(2H)-pyridazinone, belonging to a family of compounds with important agrochemical and pharmaceutical activities, was prepared from the corresponding 4,5-dichloro derivative in $92 \%$ yield $(1 \mathrm{~h}, 100 \stackrel{\circ}{\mathrm{C}}, 92 \mathrm{TON}) .{ }^{[65,66]}$

By using NHC oxime complexes 5 (Figure 1), aryl iodides, bromides and activated chlorides have been allowed to react with phenylboronic acid using $\mathrm{K}_{3} \mathrm{PO}_{4}$ as base in DMF at $120{ }^{\circ} \mathrm{C} .{ }^{[23,25]}$ However, under these reaction conditions chlorobenzene gave biphenyl in only $25 \%$ yield and 4 -chlorobenzonitrile gave 4 -cyanobiphenyl in $49 \%$ yield.

Comparative studies between polyethylenglycol (PEG) and imidazolium-derived ionic liquids as solvents for the S-M reaction using palladacycle 1 e for developing a homogeneous and reusable palladium catalytic system 
demonstrated that the activity was much higher in the first case. ${ }^{[68]}$ Decomposition of $1 \mathrm{e}$ in PEG does not occur upon prolonged heating but it occurs during the S-M reaction of 4-chloroacetophenone with phenylboronic acid (TBAB, CsOAc) at $120^{\circ} \mathrm{C}$, although the $\mathrm{Pd}$ catalyst can be recovered after extractive work-up with diethyl ether.

Activated and deactivated aryl chlorides could be cross-coupled with potassium aryltrifluoroborates under the same reaction conditions than arylboronic acids [ $\left.1 \mathrm{e}(0.01-1 \mathrm{~mol} \% \mathrm{Pd}), \mathrm{K}_{2} \mathrm{CO}_{3}, \mathrm{TBAB}\right]$ in water either under conventional heating or under $\mathrm{MW}$ irradiation at $100 \stackrel{\circ}{\circ} \mathrm{C}\left(53-91 \%\right.$ yields). ${ }^{[69]}$ In this case $\mathrm{Pd}(\mathrm{OAc})_{2}$ and $\mathrm{PdCl}_{2} \mathrm{gave}$ very poor results. Allyl and benzyl chlorides reacted also with potassium aryltrifluoroborates [1e $(0.1 \mathrm{~mol} \% \mathrm{Pd})$, $\mathrm{KOH}, \mathrm{TBAB}]$ in acetone/ $\mathrm{H}_{2} \mathrm{O}(3 / 2)$ at rt or $50 \stackrel{\circ}{\circ}(41-86 \%$ yields $) .{ }^{[69]}$

The vinylation of activated and deactivated aryl and heteraryl bromides with potassium alkenyltrifluoroborates can be carried out under water reflux [1e (1 mol\% Pd), $\left.\mathrm{K}_{2} \mathrm{CO}_{3}, \mathrm{TBAB}\right] .{ }^{[70]}$ In this case either under conventional or MW irradiation, both palladacycle $1 \mathbf{e}$ and $\mathrm{Pd}(\mathrm{OAc})_{2}$ gave the styrenes and stilbenes with similar results. The cross-coupling of potassium alkenyltrifluoroborates with allyl chlorides [1e $(0.1 \mathrm{~mol} \% \mathrm{Pd}), \mathrm{KOH}$, TBAB, acetone $/ \mathrm{H}_{2} \mathrm{O}$ ] at $50 \stackrel{\circ}{\circ} \mathrm{C}$ gave diastereoselectively the corresponding 1,4-dienes, whereas benzyl chlorides provided allylbenzenes (Scheme 15). ${ }^{[70]}$ Recycling experiments were performed for the cross-coupling of 4bromoacetophenone with potassium vinyltrifluoroborate during 5 cycles using the aqueous solution after extractive work-up of the product, which contains 86.2-103.1 ppm of Pd. Cinnamyl chloride also gave the corresponding (E)-1-phenylpenta-1,4-diene in good yields during 5 cycles, whereas benzyl chloride afforded allylbenzene in good yields only during 3 cycles.

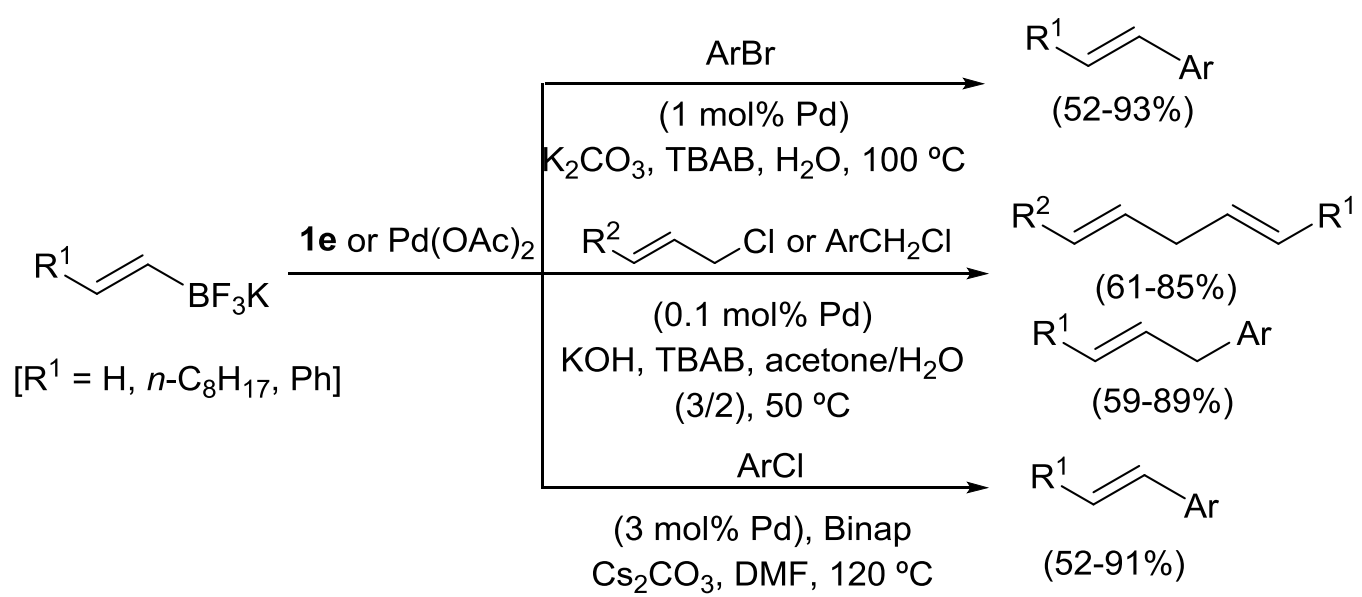

Scheme 15. S-M Reaction with potassium alkenyltrifluoroborates.

For the vinylation of activated and deactivated aryl and heteroaryl chlorides with potassium alkenyltrifluoroborates, Binap must be used as ligand, $\mathrm{Cs}_{2} \mathrm{CO}_{3}$ as base, DMF as solvent at 120 or $160{ }^{\circ} \mathrm{C}$. In this case, 1e or $\mathrm{Pd}(\mathrm{OAc})_{2}(3 \mathrm{~mol} \% \mathrm{Pd})$ showed similar catalytic efficiency palladacycle being slightly better catalyst than $\mathrm{Pd}(\mathrm{OAc})_{2}$ (Scheme 15). ${ }^{[71]}$

Hindered and deactivated aryl chlorides can be cross-coupled with arylboronic acids using $\mathbf{1 d}(0.5 \mathrm{~mol} \% \mathrm{Pd})$ in DMF. In these cases, the presence of $t-\mathrm{Bu}_{3} \mathrm{P}(1 \mathrm{~mol} \%)$ as ligand, TBAOH as additive $(20 \mathrm{~mol} \%)$, and $\mathrm{K}_{2} \mathrm{CO}_{3}$ as base at $130 \stackrel{\circ}{\circ}$ or at $160 \stackrel{\circ}{\circ}$ afforded the corresponding biphenyls in $31-99 \%$ yields under MW irradiation. ${ }^{[72]}$ However, $\mathrm{Pd}(\mathrm{OAc})_{2}$ and palladacycle $1 \mathrm{e}$ gave poorer results. The alkenylation reaction of these aryl chlorides was performed either with alkenylboronic acids or with potassium alkenyltrifluoroborates in the presence of 1d $(0.1 \mathrm{~mol} \% \mathrm{Pd}) .{ }^{[73]}$ On the other hand, this cross-coupling reaction gave poor results with methyliminodiacetic acid anhydride boronic esters (MIDA). ${ }^{[74]}$ Allyl and benzyl chlorides can be also used as substrates under these reaction conditions giving the corresponding 1,4-dienes (63-95\%) and allylbenzenes (77-86\%) in good yields.

For the S-M reaction of enols and phenols, triflates are mainly used as electrophilic partners. ${ }^{[75]}$ However, triflates have limited stability and therefore different functional groups such as mesylates, carbamates, carbonates, carboxylates, methyl ethers, phosphonium salts, phosphoramides, phosphates, borates and sulfamates have been used either under $\mathrm{Pd}$ or $\mathrm{Ni}$ catalysis in the presence of phosphanes. ${ }^{[76,77]} \mathrm{In}$ order to use this type of reagents in S-M reactions under aqueous conditions different 1-naphthol derivatives such as tert-butyl 
carbonates, N,N-dimethyl carbamates, 2-oxo-oxazolidin-3-yl phosphoramide, $\mathrm{N}, \mathrm{N}$-dimethyl sulfonamide and imidazol-1-yl sulfonate were assayed with phenylboronic acid using palladacycles $1 \mathrm{~d}$ and $\mathbf{1 e}(1 \mathrm{~mol} \% \mathrm{Pd})$. Aqueous methanol, $\mathrm{KOH}$ as base, TBAB $(20 \mathrm{~mol} \%)$ as additive at $110{ }^{\circ} \mathrm{C}$ were the appropriate reaction conditions only for the imidazol-1-yl sulfonate, which afforded 1-phenylnaphthalene in $99 \%$ and $67 \%$ yield, respectively. ${ }^{[78,79]}$ Alternatively, $\mathrm{Pd}(\mathrm{OAc})_{2}$ showed similar efficiency giving this product in $84 \%$ yield. However, when potassium phenyltrifluoroborate was used, instead of phenylboronic acid, only palladacycles 1d and 1e gave this product in $45 \%$ and $89 \%$ yield, respectively. Lower yields were obtained when phenylboronic acid pinacol ester (39\%) and MIDA ester (50\%) were used. The scope of this process was studied under conventional thermal and MW conditions not only with arylboronic acids but also with potassium aryltrifluoroborates (Scheme 16). Aryl imidazolyl sulfonates substituted with electron-withdrawing and-donating groups as well as hindered substrates were efficiently cross-coupled giving the corresponding biphenyls in high yields under MW (72-96\%) or conventional heating (53-90\%).

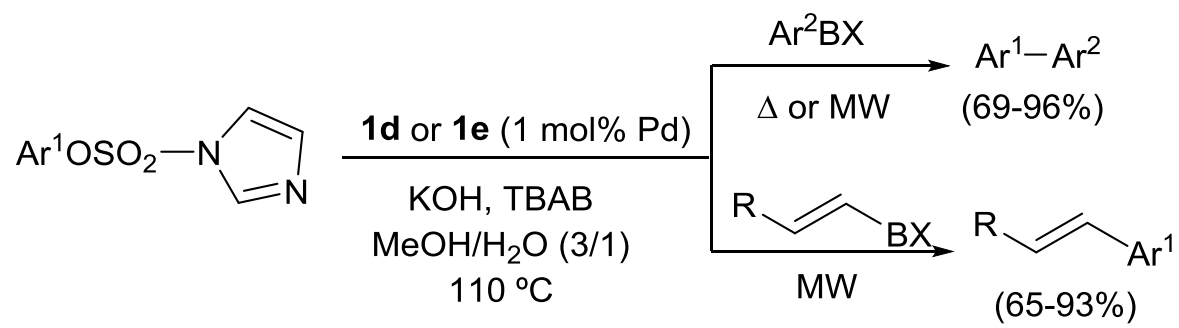

$\left[\mathrm{BX}=\mathrm{B}(\mathrm{OH})_{2}, \mathrm{BF}_{3} \mathrm{~K}\right]$

Scheme 16. S-M Reaction of aryl imidazolyl sulfonates in aqueous methanol.

The alkenylation of 1-naphthyl imidazolyl sulfonate with $(E)$-styrylboronic acid or the potassium trifluoroborate derivative were performed under conventional or $\mathrm{MW}$ irradiation. The best results were obtained under MW irradiation (40W, $\left.110^{\circ} \mathrm{C}, 30 \mathrm{~min}\right)$ with both palladacycles $1 \mathrm{~d}$ and $1 \mathrm{e}\left(70-85 \%\right.$ yields) or with $\mathrm{Pd}(\mathrm{OAc})_{2}(65 \%)$. The scope of the reaction was studied with different alkenylboronic acids and potassium alkenyltrifluoroborates, and with different substituted aryl imidazolyl sulfonates under MW irradiation leading to the corresponding stilbenoids in good yields (62-93\%) (Scheme 16). ${ }^{[78,79]}$

The same processes could be carried out in neat water at $110^{\circ} \mathrm{C}$ under $\mathrm{MW}$ irradiation in the presence of hexadecyltrimethylammonium bromide (CTAB) as surfactant. In this case, 1 e $(1 \mathrm{~mol} \% \mathrm{Pd})$ was the best source of $\mathrm{Pd}$ and triethylamine being the base of choice and potassium aryl and alkenyltrifluoroborates the best nucleophilic reagents (Scheme 17). ${ }^{[80]}$

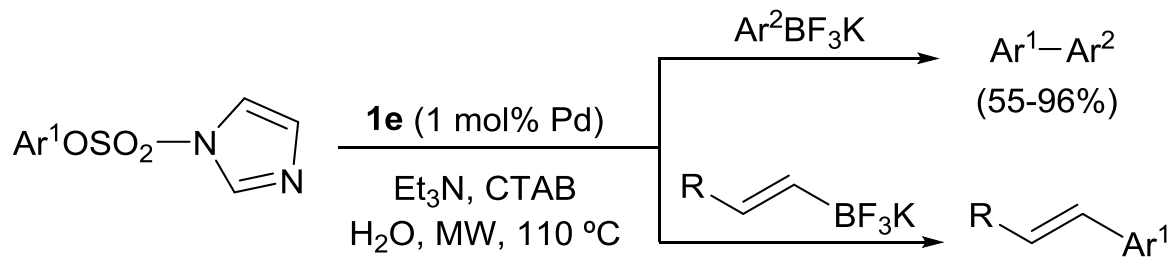

$(55-84 \%)$

Scheme 17. S-M Reaction of aryl imidazolyl sulfonates in water.

Oxime-derived palladacycle 1e covalently anchored onto a mercaptopropyl modified silica 7a ${ }^{[31]}$ (Figure 2) was initially assayed in the S-M reaction of 4-bromo and 4-chloro-acetophenone with phenylboronic acid in water using similar reaction conditions described for $1 e^{[65,66]}$ In addition, not leaching of $\mathrm{Pd}$ was detected in the reaction medium. This $\mathrm{PdL} @ \mathrm{SiO}_{2}$ 7a was used in eight consecutive cycles without detriment in the reactivity (>99\% yield) by simple filtering of the solid. ${ }^{[31]}$ However, differences in activity were observed when the oximederived palladacycle was anchored to an inorganic support MCM-41 silicate PdL@MCM-41 or topolystyrenedivinylbenzenePdL@PS 7b and ethylenglycoldimethylacrylatePdL@PEA 7c polymers (Figure 2). ${ }^{[1,82]}$ Thus, 7a 
and PdL@MCM-41 ${ }^{[82]}$ were more active than 7b and 7c, and they could be recycled at least for 7 runs. Scope studies with the four supported catalysts by Corma et al. They demonstrated that $\mathrm{PdL} @ \mathrm{SiO}_{2} 7 \mathrm{a}$ is the most active precatalyst. The imidazolium derivative 8 (Figure 2), which is soluble in 1-butyl-3-methylimidazolium-derived ionic liquid bmim $\mathrm{PF}_{6}$ and not extractable by ether, showed a satisfactory reactivity in the S-M reaction. ${ }^{[32]}$

Based on a previous described 2-pyridinealdoxime complex 12 (Figure 3), ${ }^{\left[{ }^{[3]}\right]}$ Kirschning et al. described an oxime-derived palladacycle coordinatively immobilized into polyvinylpyridine (PVP) resin 9 (Figure 2). ${ }^{[84]}$ This precatalyst exhibits high activity in the S-M reaction in batch and in continuous-flow technique for 4-bromo and 4chloroacetophenone ( $1 \mathrm{~mol} \% \mathrm{Pd}, \mathrm{K}_{2} \mathrm{CO}_{3}, 110^{\circ} \mathrm{C}$ ) in toluene or water with different arylboronic acids and very low Pd leaching. In addition, PVP also acted as scavenger for the Pd leached in the solution maintaining the catalytic activity not only in the S-M reaction but also in the $\mathrm{M}-\mathrm{H}$ reaction. ${ }^{[34,84]}$

Another strategy for the synthesis of supported palladacycles is based on the preparation of a star-shaped oxime ligand from hexakis(bromoethyl)benzene and substituted at the 4-position by a polyethyleneglycolacetophenone, which after reaction with hydroxylamine followed by palladation with $\mathrm{Li}_{2} \mathrm{PdCl}_{4}$ afforded compound 13, where the oxime ligands with Pd were coordinated through chloro-bridges (Figure 3). ${ }^{\left[{ }^{55}\right]}$ The S-M reaction takes place in the presence of $\mathbf{1 3}$ for aryl bromides with $\mathrm{K}_{2} \mathrm{CO}_{3}$ as base, $1 \mathrm{~mol} \% \mathrm{Pd}$ loading at $\mathrm{rt}$ in $\mathrm{EtOH} / \mathrm{H}_{2} \mathrm{O}$ (2/1). However, for activated aryl chlorides, 2 mol\% of Pd loading, TBAB as additive in DMF at $110{ }^{\circ} \mathrm{C}$ must be used. The catalytic activity was monitorized during 5 cycles for the reaction of very activated 4nitrochlorobenzene and phenylboronic acid with low $\mathrm{Pd}(0)$ leaching.

The Kaiser oxime-resin derived palladacycle 4 (Figure 1) initially used in $\mathrm{M}-\mathrm{H}$ reactions, ${ }^{[13,33]}$ has been employed as precatalyst in the S-M reaction. ${ }^{[86]}$ Recycling experiments have been studied for the cross-coupling of 4-bromo and 4-chloro-acetophenone with phenylboronic acid under water reflux with $\mathrm{K}_{2} \mathrm{CO}_{3}$ as base during 7 and 4 cycles with 0.01 and $1 \mathrm{~mol} \%$ Pd loadings, respectively. Moderate Pd leaching was observed and by TEM analysis of the aqueous solutions 3-10 nm PdNps were detected. The alkylation of 4-bromoacetophenone with trimethylboroxine or with $\mathrm{Bu}^{\mathrm{n}} \mathrm{B}(\mathrm{OH})_{2}$ with $\mathrm{TBAB}$ as additive in refluxing water with 5 or $1 \mathrm{~mol} \%$ Pd loading, respectively, took place during 4 cycles. Aryl bromides were alkenylated with trivinylboroxine-pyridine complex with $1 \mathrm{~mol} \%$ Pd loading during 7 and 5 cycles. In the case of styrylboronic acid 6 cycles could be performed with $0.1-05 \mathrm{~mol} \% \mathrm{Pd}$ loadings. Better recycling and lower Pd loading and leaching were observed for the arylation with phenylboronic acid of cinnamyl and benzyl chlorides using $\mathrm{KOH}$ as base, TBAB as additive in acetone $/ \mathrm{H}_{2} \mathrm{O}(3 / 2)$ with $0.1 \mathrm{~mol} \%$ of $\mathrm{Pd}$ loading at $50^{\circ} \mathrm{C}$ during 9 and 6 cycles, respectively. The alkenylation of cinnamyl and benzyl chlorides with trivinylboroxine-pyridine complex and styrylboronic acid was performed during 8 and 5 cycles, respectively. In general, the supported palladacycle 4 was isolated between $44-81 \%$ yield, in average with a $5 \% \mathrm{Pd}$ leaching in each recycling run, only aryl bromides being efficiently cross-coupled.

Recently, a polymer-supported electron-rich oxime palladacycle 14 (Figure 3) has shown better catalytic performance than Kaiser oxime resin derivative 4, but in aqueous DMF. ${ }^{[87]}$ Aryl bromides react with phenylboronic acid at $50 \stackrel{\circ}{\circ} \mathrm{C}$ with $\mathrm{K}_{2} \mathrm{CO}_{3}$ or $\mathrm{Cs}_{2} \mathrm{CO}_{3}$ as bases with $1 \mathrm{~mol} \% \mathrm{Pd}$ loading. For activated and deactivated aryl chlorides $\mathrm{Cs}_{2} \mathrm{CO}_{3}$ must be used at $100 \stackrel{\circ}{\circ}$. Recycling experiments for the cross-coupling with 4bromoanisole and $\mathrm{PhB}(\mathrm{OH})_{2}$ at $50 \stackrel{\circ}{\circ}$ could be carried out during 5 cycles with very low Pd leaching.

The ionophilic palladacycle $10^{[35]}$ (Figure 2), already mentioned in the $\mathrm{M}-\mathrm{H}$ reaction, has been used in the S-M reaction during 4 cycles in ionic liquids. The fluorous oxime palladacycle 11 ${ }^{[41,42]}$ (Figure 2), above described in the $\mathrm{M}-\mathrm{H}$ reaction, has been used in the S-M reaction of arylboronic acids, trimethylboroxine and $n$-butylboronic acid mainly with aryl and hetaryl bromides $\left(\mathrm{K}_{2} \mathrm{CO}_{3}, \mathrm{TBAB}, \mathrm{H}_{2} \mathrm{O}, 140 \stackrel{\circ}{\circ} \mathrm{C}\right)$ under $\mathrm{MW}$ irradiation with only 0.05 mol\% Pd loading. Chlorobenzene and benzyl chloride have been efficiently used with arylboronic acids without recycling experiments.

More recently, a self-supported oxime palladacycle $15^{[88]}$ based on the use of a ketone derived from 4,4'dihydroxybenzophenone and 1,12-dibromododecane has been described (Figure 3). This palladacycle with $0.77 \mathrm{mmol} / \mathrm{g} \mathrm{Pd}$ loading, was employed in the S-M reaction of aryl bromides with $\mathrm{PhB}(\mathrm{OH})_{2}$ at $80 \stackrel{\circ}{\circ} \mathrm{C}$ in $\mathrm{DMF} / \mathrm{H}_{2} \mathrm{O}$ (1/1) with $\mathrm{Cs}_{2} \mathrm{CO}_{3}$ as base. In the case of 4-bromoacetophenone (1.5 mol\% Pd loading) the catalyst was recycled 5 times with negligible leaching. However, activated aryl chlorides gave moderate yields at $100 \stackrel{\circ}{ }{ }^{\circ}$.

Searching for an easy removal of the palladacycle from the reaction medium, very recently a catalyst derived from 4-aminoacetophenone has been supported on magnetite nanoparticles coated with a thin layer of silica using a sol-gel process to give core/shell Nps. This supported palladacycle $16^{[89]}$ (Figure 3) with a $0.3 \mathrm{mmol} / \mathrm{g}$ 
loading of $\mathrm{Pd}$, showed high efficiency in aqueous $\mathrm{EtOH}(1: 1)$ at $\mathrm{rt}$ using $t$-BuOK as base and $0.3 \mathrm{~mol} \% \mathrm{Pd}$ loading for the cross-coupling of activated and deactivated aryl iodides and bromides with $\mathrm{PhB}(\mathrm{OH})_{2}$. Only activated aryl chlorides afforded moderate reactivity at $60^{\circ} \mathrm{C}$. Comparison studies on the catalytic activity of 16 with other supported oxime-derived complexes such as $\mathbf{4}$ and $\mathbf{1 4}$ for the cross-coupling of 4-bromoanisole with phenylboronic acid indicated a higher efficiency for 16. In the case of the cross-coupling of 4bromoacetophenone and phenylboronic acid, complex 16 showed better efficiency than the silica gel supported complex $\mathbf{7 a}$. With respect to recycling experiments of $\mathbf{1 6}$, for the reaction of 4-bromoanisole with phenylboronic acid at rt the efficiency could be maintained at least during 6 cycles, the complex could be recovered by means of an external magnet although $1.6 \% \mathrm{Pd}$ leaching was detected in the solution.<smiles></smiles>

12<smiles>[3H][P@]1(Cl)c2cc(OCCOCc3c(CC(C)(C)C)c(CC)c(CC(C)(C)C)c(CC(C)(C)C)c3CC(C)(C)C)ccc2C(C)N1O</smiles>

13<smiles></smiles>

14

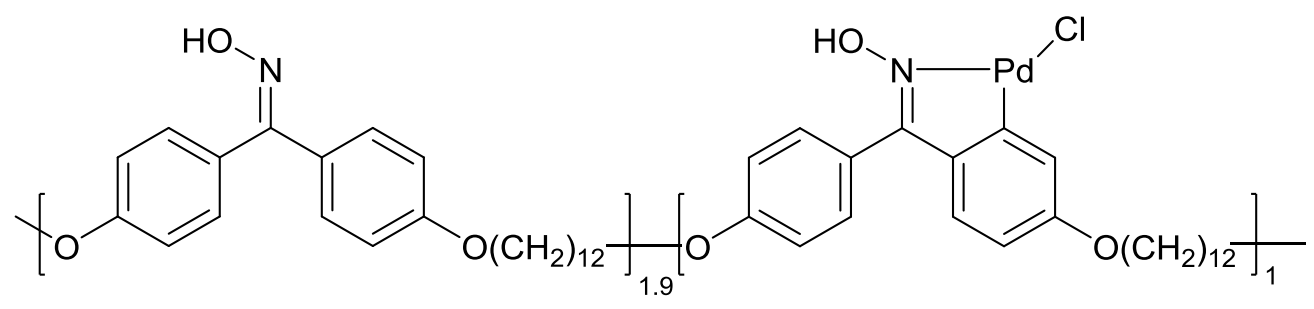

15<smiles></smiles>

16

Figure 3. Supported oxime-derived palladacycles 13-16.

\subsection{Stille reaction}

The cross-coupling of trimethyl(phenyl)stannane was initially performed with 4-bromoacetophenone under toluene reflux with palladacycles $\mathbf{1 a}-\mathbf{1 d}(3 \mathrm{~mol} \% \mathrm{Pd})$ with moderate yields. ${ }^{[18]}$ Recently, this reaction was investigated using the supported fluorous oxime palladacycle 11 (Figure 2) $(0.005 \mathrm{~mol} \% \mathrm{Pd}$ ) and tri- $n$-butyl(4methoxyphenyl)stannane, which reacts with aryl bromides in water as solvent, TBAB as additive at $100{ }^{\circ} \mathrm{C}$ under MW irradiation. Excellent yields (81-94\%) were obtained in less than 10 min. ${ }^{[41]}$ The scope of this procedure was futher studied with different aryl iodides and bromides as well as other organostannanes (Scheme 18). ${ }^{[42]}$ For recycling experiments tributyl(phenyl)stannane and iodobenzene were cross-coupled quantitatively under the 
above mentioned conditions during five runs in less than $1 \mathrm{~min}$ with 0.52-0.57 ppm Pd leaching, the catalyst 11 being recovered by fluorous solid-phase extraction (F-SPE) with fluorous silica in $91-96 \%$ yield.

$$
\begin{gathered}
\mathrm{RSn}\left(\mathrm{Bu}^{\mathrm{n}}\right)_{3}+\operatorname{ArX} \frac{11(0.005 \mathrm{~mol} \% \mathrm{Pd})}{\frac{\mathrm{H}_{2} \mathrm{O}, \mathrm{TBAB}, 100^{\circ} \mathrm{C}}{\mathrm{MW}, 0.5-6 \mathrm{~min}}} \underset{(74-95 \%)}{\mathrm{R}-\mathrm{Ar}+\mathrm{XSn}\left(\mathrm{Bu}^{\mathrm{n}}\right)_{3}} \\
{\left[\begin{array}{l}
\mathrm{R}=\text { aryl, alkynyl } \\
\mathrm{X}=\mathrm{I}, \mathrm{Br}
\end{array}\right]}
\end{gathered}
$$

Scheme 18. Stille reaction catalyzed by supported palladacycle 11.

\subsection{Kumada reaction}

For the cross-coupling of phenylmagnesium bromide (1 M) in THF and 4-bromotoluene under MW irradiation in different solvents using fluorous oxime-palladacycle 11 (Figure 2) $(0.05 \mathrm{~mol} \% \mathrm{Pd}$ ), it was found that THF was the solvent of choice giving 4-methylbiphenyl in $95 \%$ yield within $15 \mathrm{~min}$. Under the optimized reaction conditions phenyl- and vinylmagnesium bromide were allowed to react not only with aryl iodides and bromides but also with alkyl derivatives in high yields of the corresponding products (Scheme 19). ${ }^{[42]}$ Recycling experiments for the cross-coupling of bromobenzene and phenylmagnesium bromide as model reaction afforded yields ranging from $91 \%$ to $63 \%$ over 4 cycles with $0.84-0.88$ ppm Pd leaching and $90-81 \%$ catalyst recovery.

$$
\begin{aligned}
& \mathrm{R}^{1} \mathrm{MgBr}+\mathrm{R}^{2} \mathrm{X} \stackrel{11(0.05 \mathrm{~mol} \% \mathrm{Pd})}{\longrightarrow} \mathrm{R}^{1}-\mathrm{R}^{2} \\
& \text { THF, } 100^{\circ} \mathrm{C} \\
& \text { MW, } 0.5-10 \min \quad(82-96 \%) \\
& {\left[\begin{array}{l}
\mathrm{R}^{1}=\text { aryl, alkenyl } \\
\mathrm{R}^{2}=\text { aryl, alkyl } \\
\mathrm{X}=\mathrm{I}, \mathrm{Br}
\end{array}\right]}
\end{aligned}
$$

Scheme 19. Kumada reaction catalyzed by supported palladacycle 11.

\subsection{Hiyama reaction}

In order to perform the Hiyama reaction under fluoride-free conditions 50\% aqueous sodium hydroxide (2.5 eq) could be used as promoter and reaction medium for the cross-coupling of aryl chlorides and bromides with aryltrialkoxysilanes under conventional thermal or MW conditions at $120{ }^{\circ} \mathrm{C} .{ }^{[90]}$ This protocol has been performed with $0.1 \mathrm{~mol} \% \mathrm{Pd}$ for the cross-coupling of 4-bromoanisole and trimethoxy(phenyl)silane using palladacycles 1d and 1e as $\mathrm{Pd}$ source (Figure 1) but also $\mathrm{Pd}(\mathrm{OAc})_{2}$ or $\mathrm{PdCl}_{2}$ in a pressure tube at $120{ }^{\circ} \mathrm{C}$ being the former palladacycle the best precatalyst. The scope of this procedure showed high yields with rather low Pd loading (0.001-0.1 mol\%) either during 10 min under MW irradiation or 1 to $5 \mathrm{~h}$ at $120{ }^{\circ} \mathrm{C}$ bath temperature (Scheme 20). Different arylsiloxanes can be used although silicone was less reactive. Recycling experiments were efficiently performed for the cross-coupling of 4-bromoanisole and 4-bromoacetophenone with trimethoxy(phenyl)silane during 5 cycles of $3 \mathrm{~h}$ and $1 \mathrm{~h}$, respectively. The corresponding products were isolated by extractive work-up and the solid residue was reused by adding new reagents. 


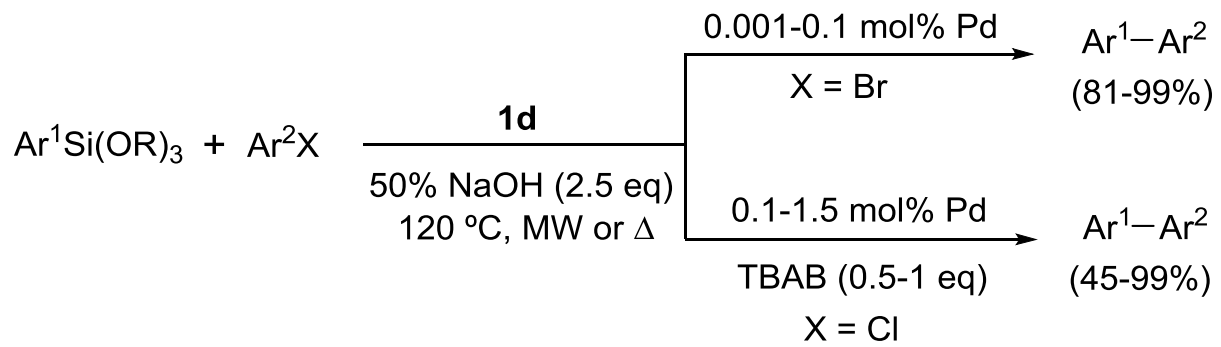

Scheme 20. Hiyama arylation catalyzed by palladacycle $\mathbf{1 d}$.

For the alkenylation reaction under fluoride-free conditions by means of trialkoxy(alkenyl)silanes aqueous $\mathrm{NaOH}$ as base and promoter and TBAB as additive were used for aryl iodides, bromides and chorides under conventional or MW irradiation. ${ }^{\text {[91,92] }}$ In this case, either palladacycle $1 \mathrm{e}$ or $\mathrm{Pd}(\mathrm{OAc})_{2}$ were active giving similar results. The scope of the reaction was studied under MW irradiation at $120 \stackrel{\circ}{\circ}$ for $10-30$ min using vinyl, styryl and octenyl(trimethoxy)silanes (Scheme 21). Generally, the configuration of the alkenylsiloxane was maintained in the final alkene. Recycling experiments were performed by extractive work-up and using the aqueous layer for the next run. In the case of $\mathrm{Pd}(\mathrm{OAc})_{2}$ a maximum of 4 runs could be performed, whereas with $1 \mathrm{e}$ at least 6 cycles could be efficiently performed (95-99\% yield) with 3.6-76.4 ppm Pd leaching for $\mathrm{Pd}(\mathrm{OAc})_{2}$ and 3.6-90.5 ppm for $1 e$.

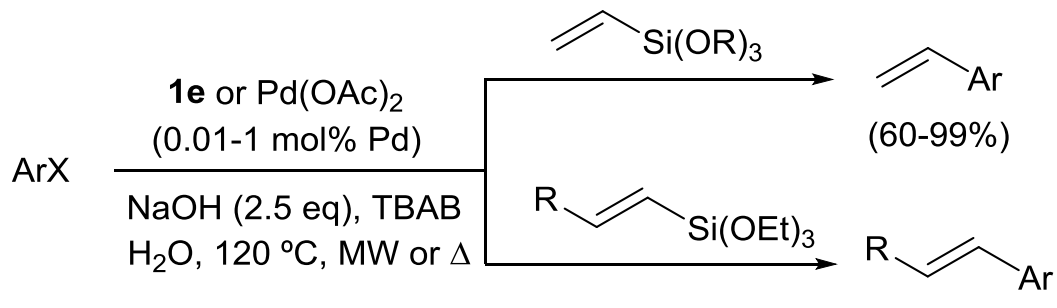

$(\mathrm{X}=\mathrm{I}, \mathrm{Br}, \mathrm{Cl})$

$(70-99 \%)$

Scheme 21. Hiyama alkenylation catalyzed by palladacycle 1 e.

\subsection{Ullman reaction}

The homocoupling of aryl iodides was performed using 1d (Figure 1) $(0.5 \mathrm{~mol} \% \mathrm{Pd}$ ) and diisopropylethylamine (DIPEA) in DMF at $110{ }^{\circ} \mathrm{C}$ taking place in 5-7 $\mathrm{h}$ reaction time (Scheme 22). ${ }^{63]} \mathrm{A}$ proposed mechanism for these type of Ullman reaction involves the oxidation of the tertiary amine by $\mathrm{Pd}(\mathrm{II})$ with formation of a $\mathrm{Pd}(\mathrm{IV})$ complex with both aryl units, which after reductive elimination produces the biaryl, an iminium salt and hydrogen iodide. ${ }^{\left[{ }^{[3]}\right.}$

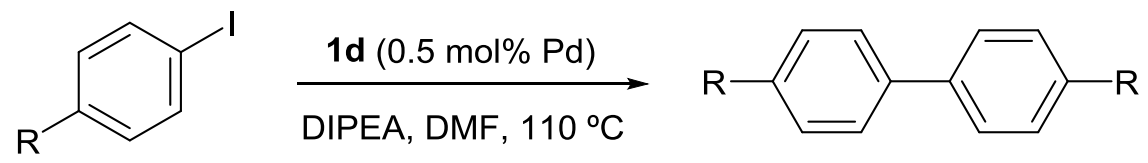

$(83-99 \%)$

$$
\left[\mathrm{R}=\mathrm{H}, \mathrm{OMe}, \mathrm{Ac}, \mathrm{Cl}, \mathrm{F}, \mathrm{NO}_{2}\right]
$$

Scheme 22. Homocoupling of aryl iodides.

$\mathrm{N}$-Heterocyclic carbene palladacycle $5 \mathbf{b}$ (Figure 1) $(0.09 \mathrm{~mol} \%)$ has shown catalytic activity in the homocoupling of aryl iodides and 2-bromopyridine in the presence of $\mathrm{Zn}$ dust $(1 \mathrm{eq})$ in DMF at $110{ }^{\circ} \mathrm{C}$ affording biaryls in modest yields. ${ }^{[23]}$ 


\section{Alkynylation reactions}

\subsection{Cassar-Heck-Sonogashira reaction}

Initially, palladacycles 1a-1d $(0.5 \mathrm{~mol} \% \mathrm{Pd})$ were used for the alkynylation of iodobenzene with phenylacetylene in the presence of $\mathrm{Cul}(5 \mathrm{~mol} \%)$ and pyrrolidine as solvent at $90{ }^{\circ} \mathrm{C}$, which are typical Sonogashira reaction conditions ${ }^{[18]}$ However, the alkynylation of aryl iodides and bromides could be performed in the absence of Cul using 1d (0.1-0.5 mol\% Pd), tetra- $n$-butylammonium acetate (TBAA) as base in $N$-methylpyrrolidone (NMP) at

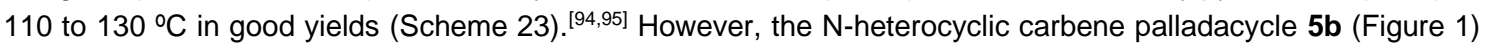
failed in the same process. ${ }^{[23]}$

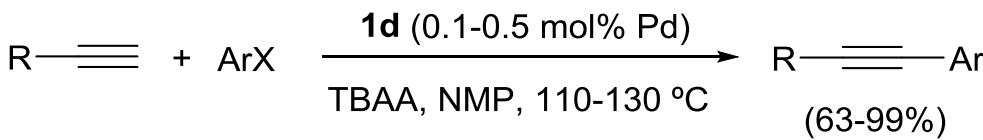

$$
\begin{aligned}
& {\left[\begin{array}{l}
R=\text { aryl, alkyl, } \operatorname{Pr}_{3}^{\mathrm{i}} \mathrm{Si} \\
\mathrm{X}=\mathrm{I}, \mathrm{Br}
\end{array}\right]}
\end{aligned}
$$

Scheme 23. Copper- and amine-free alkynylation of aryl halides.

When trimethylsilyl- (TMSA) and bis(trimethylsilyl)acetylene (BTMSA) were used as alkynylating reagents the sila-Sonogashira reaction could be selectively performed. Diarylation with aryl iodides and bromides occurred when TMSA and BTMSA were allowed to react in the presence of Cul (5 mol\%) as cocatalyst and pyrrolidine as solvent at $90{ }^{\circ} \mathrm{C}$. These processes take place via protodesilylation previous to the arylation reaction, these silylated acetylenes being synthetic equivalents of acetylene. However, in the presence of TBAB as additive and pyrrolidine as base in NMP at $110{ }^{\circ} \mathrm{C}$ the monoarylation occurred giving the corresponding silylated acetylenes (Scheme 24). ${ }^{[95]}$

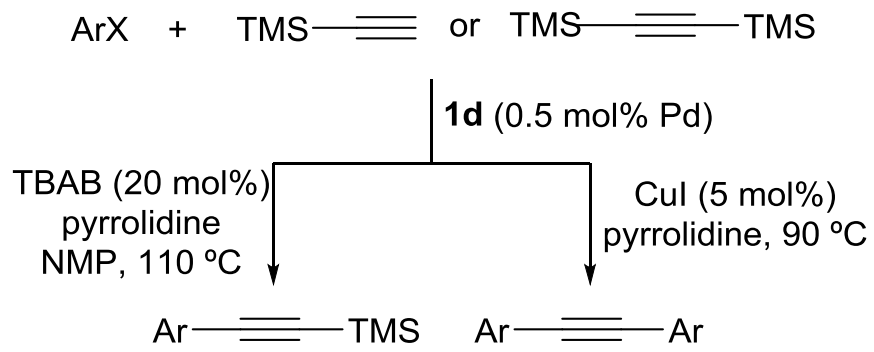

Scheme 24. Mono- and diarylation of silylated acetylenes.

By employing polyethyleneglycol (PEG) as solvent the alkynylation of aryl bromides and chlorides can be performed with the palladacycle 1e under copper-free conditions using CsOAc as base at $120{ }^{\circ} \mathrm{C}$. ${ }^{[68]}$ Under these reaction conditions 4-bromo- and 4-chloroacetophenone reacted with phenylacetylene in a 50:1 solvent:substrates ratio in good yields. After hot liquid-liquid extraction the corresponding internal acetylenes can be isolated and the solvent containing $\mathrm{Pd}$ can be reused 5 times without any loss of efficiency. Similar results have been obtained in the previous mentioned S-M reaction (Section 3.1).

Water has been used also as solvent for the alkynylation of aryl bromides and activated aryl chlorides in the presence of fluorous oxime-palladacycle 11 (Figure 2) $(0.5 \mathrm{~mol} \% \mathrm{Pd}) .{ }^{[41,42]}$ The process took place at $140{ }^{\circ} \mathrm{C}$ under MW irradiation (7-30 min) using pyrrolidine as base $(0.5 \mathrm{eq})$ under copper-free conditions in high yields (87-95\%). The recycling experiments were performed for the reaction of 4-nitrobromobenzene with phenylacetylene during five runs in 93-89\% yields with low Pd leaching (0.067-0.073 ppm).

The first example on the Sonogashira reaction in water using phenol derivatives as substrates has been described for imidazolyl sulfonates under copper-free conditions. The alkynylation takes place in the presence of SPhos, hexadecyltrimethylammonium bromide (CTAB) as surfactant and triethylamine as base under MW irradiation at $130^{\circ} \mathrm{C}$ (Scheme 25). Several Pd sources such as palladacycles $1 \mathbf{d}$ and 1e (Figure 1) as well as 
$\mathrm{Pd}(\mathrm{OAc})_{2}$ can be used, although 1e was the most efficient precatalyst. Electron-rich and -poor phenols and hindered derivatives can be successfully used with different terminal alkynes. ${ }^{[96]}$

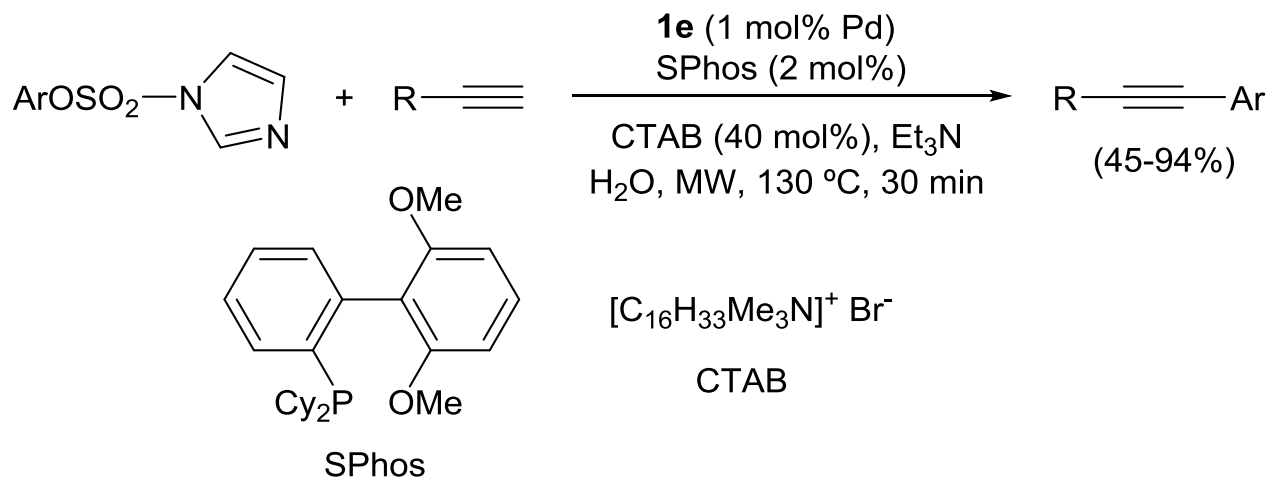

Scheme 25. Alkynylation of imidazolyl sulfonates.

Similar reaction conditions have been applied to the alkynylation of activated, deactivated and hindered aryl chlorides using XPhos as ligand, sodium dodecylbenzenesulfonate (SDBS) as surfactant and pyrrolidine as base (Scheme 26). ${ }^{[97]}$ The same process has been applied to aryl bromides just using $0.1 \mathrm{~mol} \%$ instead of $1 \mathrm{~mol} \%$ of palladacycle 1e. In the case of 1-phenyl-2-(trimethylsilyl)acetylene, the sila-Sonogashira reaction took place with 4-bromo- and 4-chloroanisole in $70 \%$ and $51 \%$ yield, respectively.

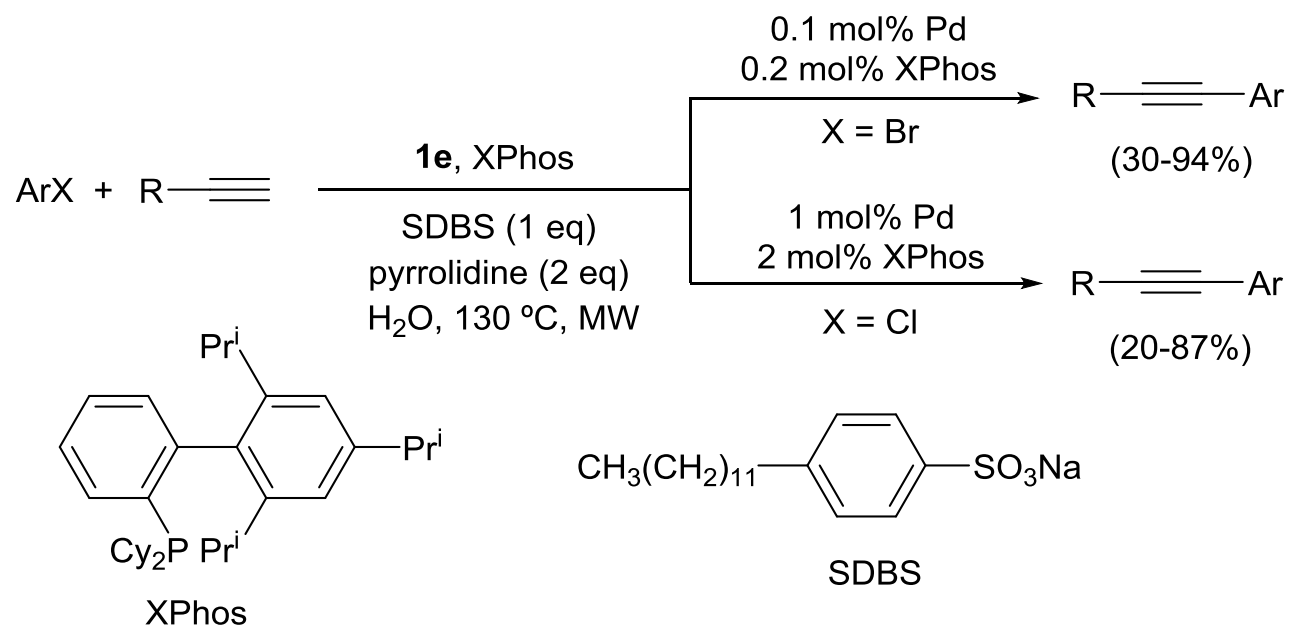

Scheme 26. Alkynylation of aryl chlorides and bromides in water.

Starting from 2-bromobenzyl and 2-chlorobenzyl alcohols, the Sonogashira reaction with terminal alkynes took place with subsequent annulations to give dihydroisobenzofurans using $\mathrm{KOH}$ as base and $\mathrm{MeOH}$ as solvent under MW irradiation at $130 \stackrel{\circ}{\circ}$ for 15 min. Palladacycle 1 d or 1 e $(1 \mathrm{~mol} \% \mathrm{Pd})$ or $\mathrm{PdCl}_{2}$ as well as $\mathrm{Pd}_{2}\left(\mathrm{dba}_{3}\right.$ as Pd source and XPhos as ligand can be used, although 1d gave slightly better results (Scheme 27). ${ }^{[98]}$ Under the same reaction conditions the corresponding 2-halogenated benzaldehydes were alkynylated affording 3methoxy-1,3-dihydroisobenzofurans (Scheme 27). 


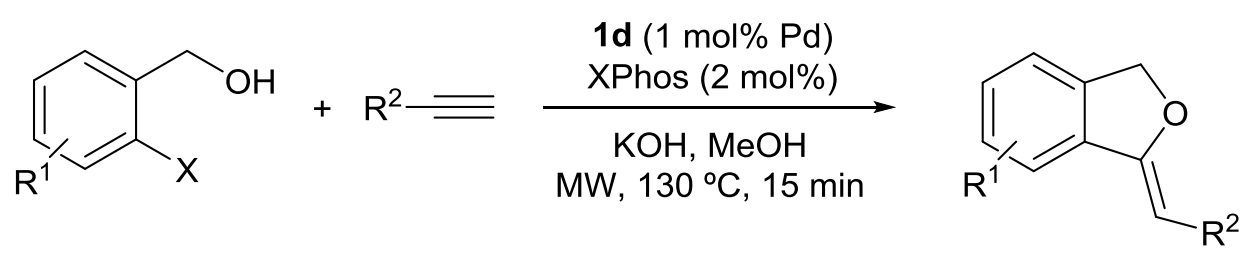

$$
\begin{aligned}
& X=\mathrm{Br}: 72-94 \% \\
& \mathrm{X}=\mathrm{Cl}: 48-84 \%
\end{aligned}
$$

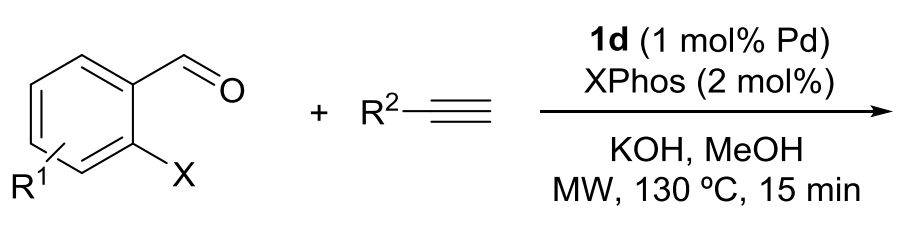<smiles>[R]C=C1OC(OC)c2ccccc21</smiles>

$(50-79 \%)$

Scheme 27. Synthesis of dihydroisobenzofurans.

\subsection{Alkynes dimerization}

Glaser-type homocoupling reaction of terminal alkynes is a direct way to prepare symmetrical diynes. The presence of $\mathrm{Cul}$ is crucial to achieve high yields in this oxidative homocoupling reaction using palladacycle 1d (Figure 1) $(0.05-0.5 \mathrm{~mol} \% \mathrm{Pd})$, NMP as solvent and pyrrolidine as base at $110 \stackrel{\circ}{\circ}$, the presence of air being important to accelerate this process (Scheme 28 ). ${ }^{[95]}$

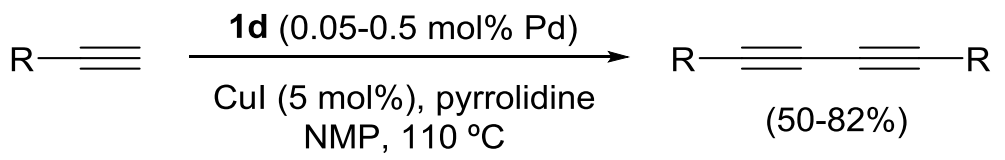

$$
\begin{aligned}
& \text { [R = alkyl, aryl, } \left.\operatorname{Pr}_{3}{ }_{3} \mathrm{Si}\right]
\end{aligned}
$$

Scheme 28. Homocoupling of terminal alkynes.

This process can be performed in water using the fluorous oxime-palladacycle 11 (Figure 2) $(0.5 \mathrm{~mol} \% \mathrm{Pd})$, Cul ( $5 \mathrm{~mol} \%$ ) and pyrrolidine as base in water at $140{ }^{\circ} \mathrm{C}$ under $\mathrm{MW}$ irradiation affording diynes in $88-99 \%$ yields. ${ }^{[42]}$

Head-to-head dimerization of terminal alkynes to give conjugated $E$-enynes has been recently carried out stereoselectively using palladacycle 1d (Figure 1) $(1 \mathrm{~mol} \% \mathrm{Pd}$ ) and an imidazolium chloride, as precursor of the corresponding carbene, triethylamine as base, TBAB as additive in water at $130{ }^{\circ} \mathrm{C}$ under MW irradiation (Scheme 29). ${ }^{[99]}$ This type of dimerization has been proposed to proceed via a hydropalladation pathway according to DFT calculations. ${ }^{[100]}$ 


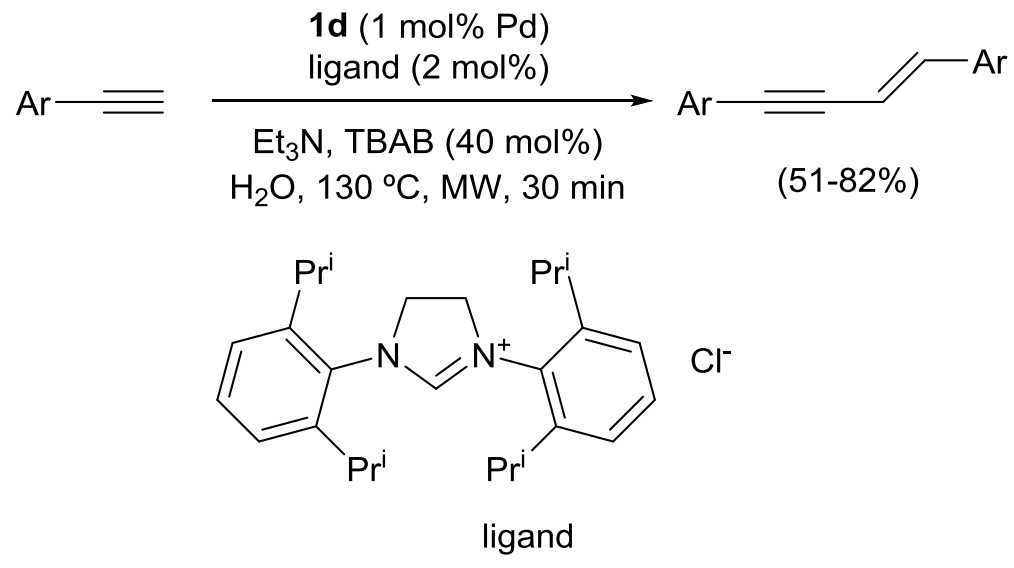

Scheme 29. Head-to head dimerization of terminal alkynes.

\section{Buchwald-Hartwig amination}

This type of amination has been studied by lyer et al. with little success only for the reaction of bromobenzene with morpholine to give $\mathrm{N}$-phenylmorpholine in the presence of $\mathbf{5 b}$ (Figure 1 ) in a modest $30 \%$ yield using potassium tert-butoxide as base under toluene reflux. ${ }^{[23,25]}$

\section{Carbonylation reactions}

Under phosphine-free conditions the copper-free acylation of terminal alkynes with carboxylic acid chlorides could be carried out either with palladacycle 1d (Figure 1) or $\mathrm{Pd}(\mathrm{OAc})_{2}(0.2-0.5 \mathrm{~mol} \% \mathrm{Pd}$ ) in toluene and triethylamine $(3 \mathrm{eq})$ as base at $\mathrm{rt}$ or $110 \stackrel{\circ}{\circ} \mathrm{C}$ (Scheme 30). ${ }^{[101]}$ The corresponding ynones are isolated in high yields under air, and only when very reactive acyl chlorides are used inert atmosphere was necessary.

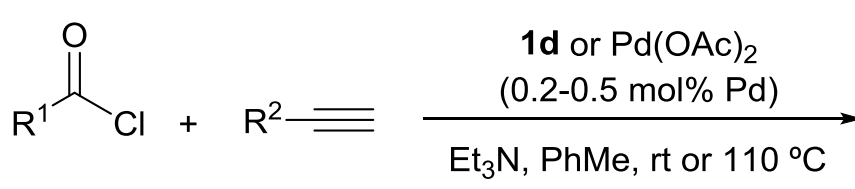<smiles>[R]C#CC([R])=O</smiles>

$(56-99 \%)$

Scheme 30. Acylation of terminal alkynes.

Recently, the carbonylation of aryl iodides and bromides with arylboronic acids has been described using the fluorous oxime-palladacycle 11 (Figure 2) (1 mol\% Pd) in water at $140{ }^{\circ} \mathrm{C}$ under $\mathrm{MW}$ irradiation in the presence of DIPEA as base and $\mathrm{Mo}(\mathrm{CO})_{8}$ as source of carbon monoxide giving diaryl ketones (Scheme 31). ${ }^{[102]}$ This carbonylation reaction has been also carried out with alcohols under neat conditions at $130{ }^{\circ} \mathrm{C}$ to afford the corresponding esters. When amines are used as nucleophiles the corresponding amides can be prepared in water at 110 or $120^{\circ} \mathrm{C}$ in good yields. For the recycling experiments 1 eq of TBAB was used as additive. Thus, 5 runs could be successfully performed for every carbonylation reaction maintaining the catalytic activity and with a very low Pd leaching (0.05-0.09 ppm). The catalyst 11 was recovered in $74-95 \%$ yields by F-SPE with fluorous silica column. This methodology has been applied to the synthesis of 2-(naphthalene-2-yl)-1-phenylethanone in $54 \%$ yield, precursor of a reverse transcriptase inhibitor as well as of niacin (nicotinic acid) as ethyl ester or as acid by adding water instead of ethanol ( $81 \%$ yield). Other relevant examples are, ethyl 4 -aminobenzoate or benzocaine $(88 \%$ yield), butyl 4 -aminobenzoate or butamben $(90 \%$ yield) and methyl aminohippurate $(71 \%$ yield) from the corresponding aryl iodides. 


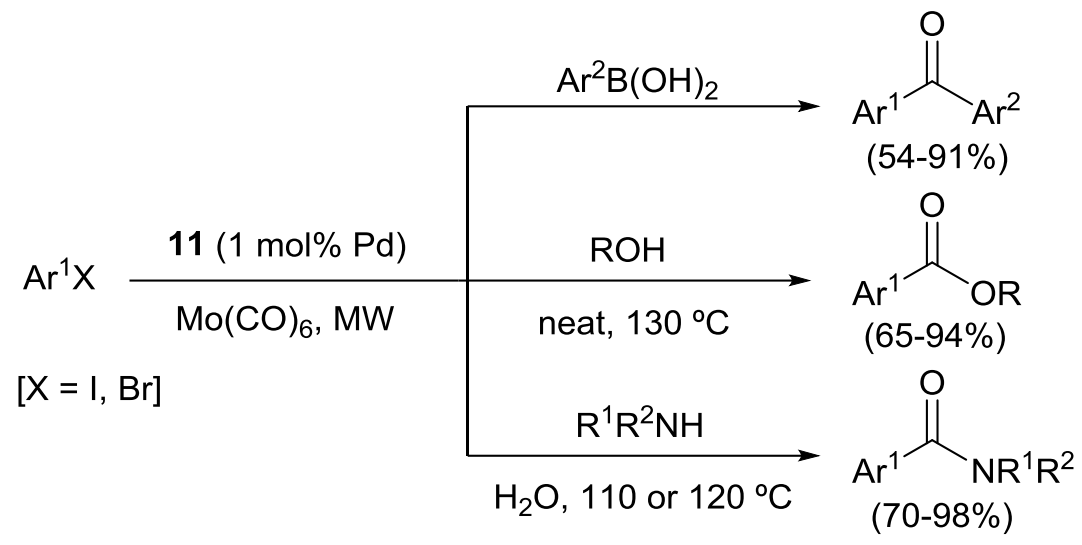

Scheme 31. Carbonylation of aryl halides.

\section{Annulations}

Annulations of internal alkynes with 2-halogen substituted aromatic aldehydes and anilines, developed by Larock et al. ${ }^{[103,104]}$ is a direct way for the synthesis of indenones and indoles, respectively. These processes can be carried out with only $0.5 \mathrm{~mol} \%$ of palladacycle 1d (Figure 1) for the reaction of diphenylacetylene with 2bromo- and 2-chlorobenzaldehyde, $\mathrm{K}_{2} \mathrm{CO}_{3}$ as base and TBAB as additive in DMF at $130 \stackrel{\circ}{\circ}$ affording the indenone in $98 \%$ and $94 \%$ yield, respectively (Scheme $32 \mathrm{a}$ ). ${ }^{[19]}$ In the case of 2-iodoaniline and different internal alkynes the corresponding indoles were obtained (47-98\% yields) under the same reaction conditions (Scheme 32b). ${ }^{[19]}$ By using the supported Kaiser oxime-palladacycle 4 (Figure 1) (1 mol\% Pd), diphenylacetylene reacts with 2-bromobenzaldehyde giving the corresponding indenone in $92 \%$ yield in aqueous DMF with $\mathrm{Cy}_{2} \mathrm{NMe}$ as base at $120{ }^{\circ} \mathrm{C}$ and 2 -iodoaniline the corresponding indole in $99 \%$ yield. ${ }^{[33]}$<smiles>[X]c1ccccc1C=O</smiles><smiles>Nc1ccccc1I</smiles><smiles>[R]C#C[CH2-]</smiles>

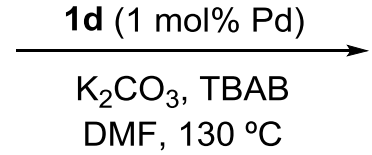<smiles>O=C1C(c2ccccc2)=C(c2ccccc2)c2ccccc21</smiles>

$$
\mathrm{X}=\mathrm{Br}, 2 \mathrm{~h}, 98 \%
$$$$
\mathrm{X}=\mathrm{Cl}, 6 \mathrm{~h}, 94 \%
$$<smiles>[R]c1[nH]c2ccccc2c1[R]</smiles>

$$
\begin{aligned}
& \mathrm{R}=\mathrm{Pr}, 9 \mathrm{~h}, 93 \% \\
& \mathrm{R}=\mathrm{Ph}, 10 \mathrm{~h}, 98 \% \\
& \mathrm{R}=\mathrm{TMS}, 4 \mathrm{~h}, 47 \%
\end{aligned}
$$

Scheme 32. Synthesis of indenones and indoles.

These annulations have been carried out in water using either the fluorous oxime-palladacycle 11 (Figure 2) (1 mol\% $\mathrm{Pd}$ ) or $\mathrm{Pd}(\mathrm{OAc})_{2}(5 \mathrm{~mol} \% \mathrm{Pd})$ with $\mathrm{Na}_{2} \mathrm{CO}_{3}$ as base, TBAB as additive at $150{ }^{\circ} \mathrm{C}$ under $\mathrm{MW}$ irradiation leading to indenones (30-91\%) and indoles (62-94\%). ${ }^{[105]}$ This methodology has been also applied to the synthesis of 2,3-disubstituted 1-indenols from 2-iodo and 2-bromoacetophenone (Scheme 33a). 2Naphthylamines have been prepared starting from 2-(2-iodophenyl)acetonitrile (Scheme 33b). 3,4-Disubstituted isocoumarins resulted from the annulations between internal alkynes and methyl 2-iodobenzoate (Scheme 33c). Starting from 2-iodobenzyl alcohols, 3,4-disubstituted-1H-isochromenes can be prepared (Scheme 33d) and 2,3disubstituted benzofurans from 2-iodophenol or 1-acethoxy-2-iodobenzene (Scheme 33e). Finally, the synthesis 
of 3,4-disubstituted isoquinolines have been synthesized by using 2-iodobenzaldimines and internal alkynes (Scheme 33f). Reycling experiments have been carried out in the case on indoles, indenols and isocoumarins during 5 cycles recovering the catalyst in $62-90 \%$ yields and with only $0.15-0.54 \mathrm{ppm}$ Pd leaching.

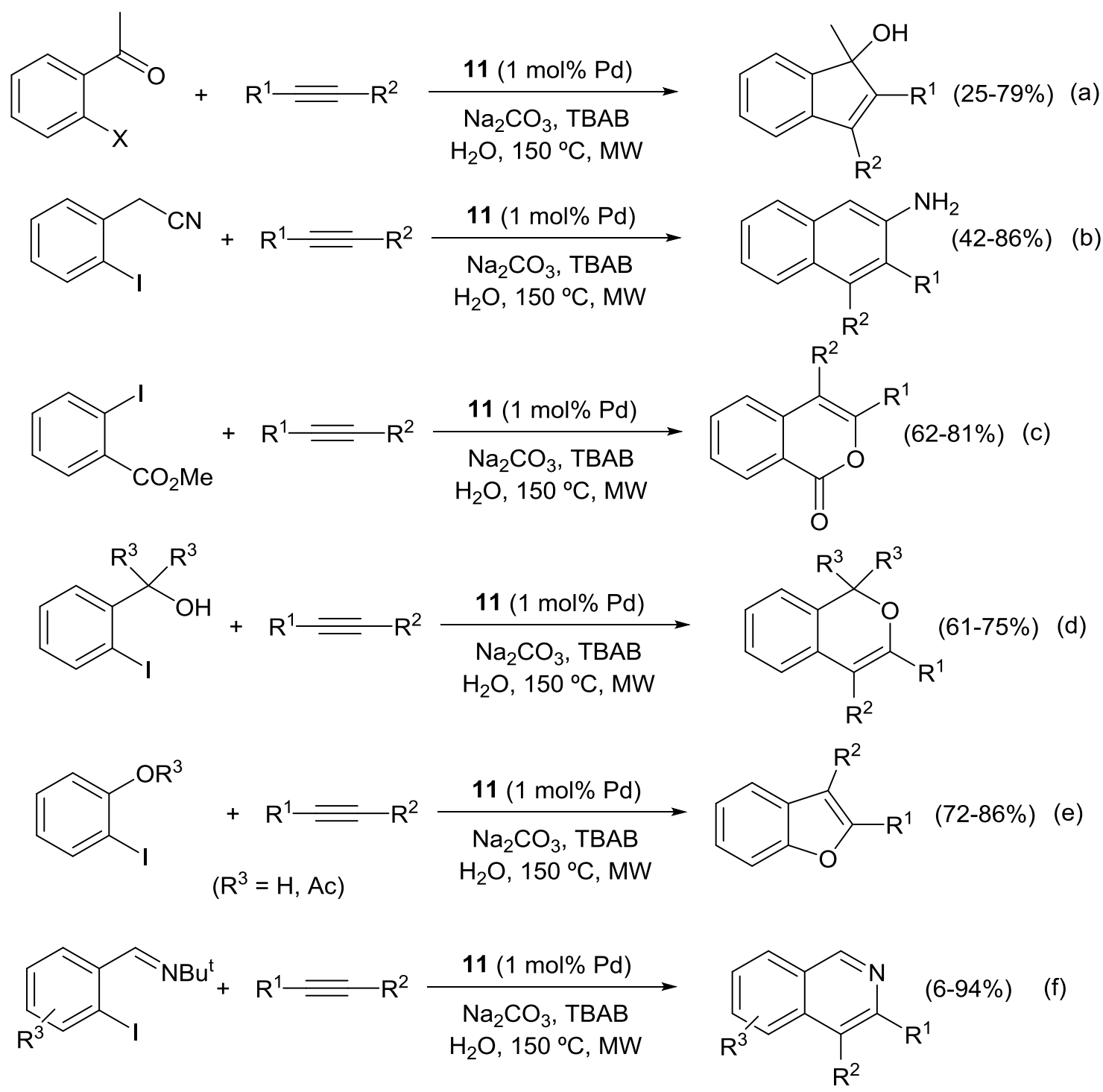

Scheme 33. Annulation reactions with terminal alkynes.

For the synthesis of quinolines from 2-iodoaniline, allylic alcohols ${ }^{[48]}$ or $\mathrm{MBH}$ adducts ${ }^{[106]}$ have been used as a 3 component reaction. In the former case, $\mathrm{Cy}_{2} \mathrm{NMe}$ was used as base, TBAB as additive and $\mathrm{DMA} / \mathrm{H}_{2} \mathrm{O}(4 / 1)$ as solvents at $120{ }^{\circ} \mathrm{C}$ (Scheme 34a). In the presence of palladacycle 1d (Figure 1) (1 mol\% Pd) the last annulation takes place in higher yields than with $\mathrm{Pd}(\mathrm{OAc})_{2}$ using $\mathrm{DMF}$ as solvent and $\mathrm{Et}_{3} \mathrm{~N}$ as base at $110{ }^{\circ} \mathrm{C}$ under air (Scheme 34b). ${ }^{[106]}$ In both cases the intermediacy of the carbonyl compound (see, Schemes 7 and 9), which condensed with the amino group has been proposed. The aromatization of the resulting dihydroquinolines can be explained by the presence of air. Alternatively, this dehydrogenative process can takes place by $\mathrm{C}-\mathrm{H}$ activation-palladation at the benzylic position followed by $\beta$-hydride elimination. ${ }^{106]}$ 
<smiles>Nc1ccccc1I</smiles><smiles>[R]C(O)C=C</smiles>

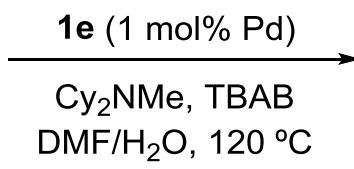<smiles>[R]c1ccc2ccccc2n1</smiles>

(a)<smiles>Nc1ccc[R1]c1I</smiles><smiles>[R]OC(=C)C([R])O</smiles><smiles>CCN(CC)O[Mg]</smiles><smiles>[R]OC(=O)c1cc2ccccc2nc1[R]</smiles>

$(45-89 \%)$

Scheme 34. Annulation reactions with allylic alcohols.

Microwave-promoted oxyarylation of dihydronaphthalene and chromenes by 2-iodophenols or its acetates has been performed using oxime-derived palladacycle $1 \mathrm{e}(2 \mathrm{~mol} \% \mathrm{Pd}), \mathrm{Cy}_{2} \mathrm{NMe}$ as base in aqueous DMA at $120{ }^{\circ} \mathrm{C}$. Alternatively $\mathrm{Pd}(\mathrm{OAc})_{2}(10 \mathrm{~mol} \%)$ in acetone as solvent at $60{ }^{\circ} \mathrm{C}$ can be used in the presence of an excess of $\mathrm{Ag}_{2} \mathrm{CO}_{3}$ (1.5 eq) as base (Scheme 35). ${ }^{[107]}$ This process has been also carried out in PEG-400 in higher yields. ${ }^{[108]}$ This methodology allows the synthesis of dihydro-5-carbapterocarpans and pterocarpanquinones in only one operational step with total control of the steroselectivity. They present antineoplasic activity in human cancer cell lines and antileishmanial activity in culture and in mice.

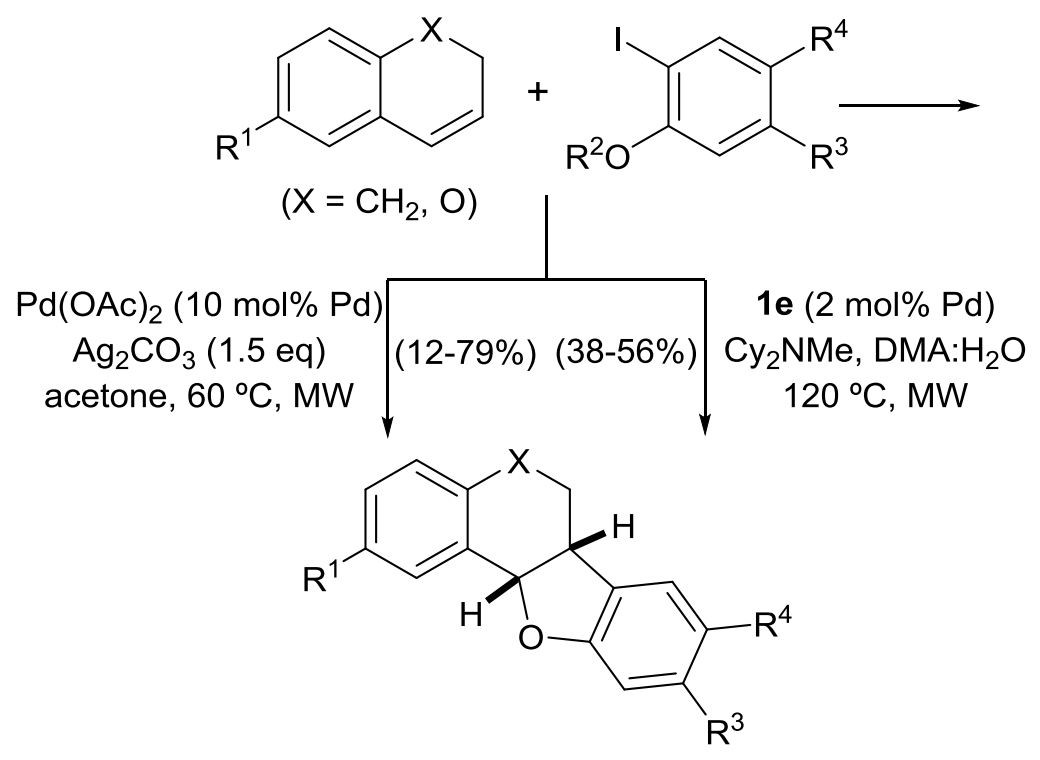

Scheme 35. Oxyarylation of dihydronaphthalenes and chromenes.

5-Carbapterocarpens have been also prepared in two steps by arylation of tetralones with 2methoxybromoarenes followed by tandem demethylation/cyclization with $\mathrm{BBr}_{3}$. The palladium-catalyzed arylation has been carried out with $\mathrm{Pd}_{2}(\mathrm{dba})_{3}$ or palladacycle $1 \mathrm{~d}(2.5 \mathrm{~mol} \% \mathrm{Pd})$ under $\mathrm{MW}$ irradiation in the presence of $\mathrm{Bu}_{3} \mathrm{PHBF}_{4}(10 \mathrm{~mol} \%), \mathrm{KOH}$ as base in dioxane/water (4/1) at $100{ }^{\circ} \mathrm{C}$ under MW irradiation (Scheme 36). ${ }^{[109]}$ 


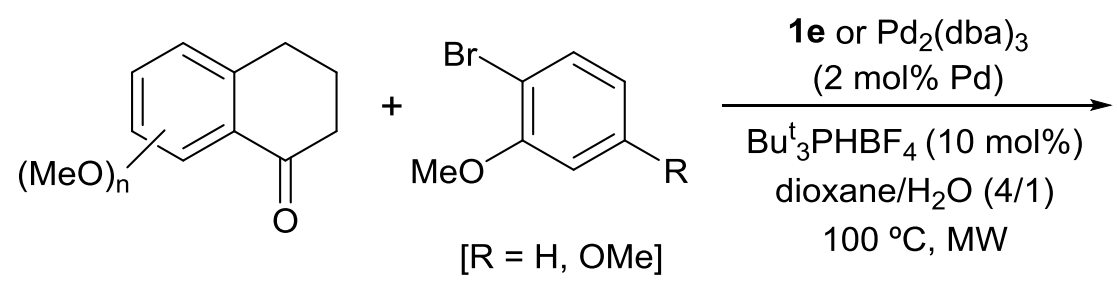<smiles>[R]c1ccc(C2CCc3cccc(OC)c3C2=O)c(OC)c1</smiles>

$(67-90 \%)$<smiles>Oc1ccc2c3c(oc2c1)-c1c(O)cccc1CC3</smiles>

Scheme 36. Synthesis of 5-carbapterocarpens.

The first intramolecular Pauson-Khand reaction (PKR) catalyzed by palladacycles has been performed efficiently with the pyridine complex of acetophenone oxime-palladacycle 9 (Figure 2) (10 mol\%) in dimethoxyethane (DME) at $130{ }^{\circ} \mathrm{C}$ and $2 \mathrm{~atm} \mathrm{CO}$ pressure at rt. ${ }^{[110]}$ Allyl propargyl ethers and amines as well as malonates are transformed efficiently into the corresponding fused cyclopentenones (Scheme 37). The presence of $\mathrm{LiCl}$ and pyridine play a critical role for the catalytic cycle of these PKRs, the chloride being essential for the chloropalladation of the alkyne moiety, ${ }^{[111]}$ and therefore a $\mathrm{Pd}(\mathrm{II})-\mathrm{Pd}(\mathrm{IV})$ mechanism has been proposed.

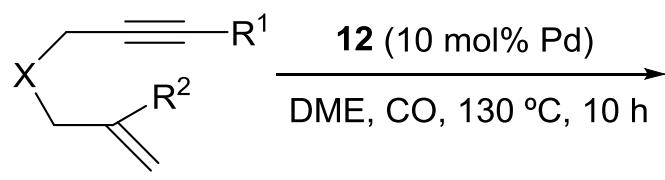

$\left[\mathrm{X}=\mathrm{O}, \mathrm{NTs}, \mathrm{C}\left(\mathrm{CO}_{2} \mathrm{Et}\right)_{2}\right]$<smiles>[X]CC12CCC1=C([R])C(=O)C2</smiles>

$(31-97 \%)$

Scheme 37. Intramolecular PKR.

\section{Hydrolytic processes}

Biomimetic behaviour of oxime-derived palladacycles as metallohydrolases has been applied in several type of hydrolysis such as activated carboxylic and phosphoric acid esters. The hydrolysis of activated esters was first performed with oxime palladacycle $17^{[112]}$ and improved with the water soluble complex $18^{[113]}$ attached to a 5crown-15 motif (Scheme 38). This palladacycle 18 is more than ten times water soluble than a related complex without the crown ether and its solubility increases in the presence of magnesium salts. ${ }^{[12]}$ Hydrolysis of 4-nitroand 2,4-dinitrophenylcarboxylates takes place ca. $10^{3}$ times faster than the respective oxime palladacycle 17. ${ }^{[112]}$ Intermediate 19 is the most reactive catalyst and a $O$-acylated oxime complex $\mathbf{2 0}$ has been postulated as intermediate due to its rapid hydrolysis ability (Scheme 38 ).

In the case of palladacycle 18 the hydrolysis of 4-nitrophenyl 2,3-dihydroxybenzoate was choosen for modeling the catalysis by serine proteases, takes place 120-fold faster than with complex 17 in a wide catalyst concentration range at $\mathrm{pH}=8$. The proposed mechanism involves the formation of intermediates 19 and 20 because the hydrolysis of 4-nitrophenyl salicylate and benzoate is not catalyzed by $18 .{ }^{[113]}$ 
<smiles></smiles>

17<smiles></smiles>

18<smiles></smiles>

19<smiles></smiles>

20

Scheme 38. Palladacyles involved in hydrolytic processes.

Palladium and specially platinum oxime metallacycles have been shown excellent catalytic activity for the hydrolysis of thiophosphate pesticides and neurotoxins. ${ }^{[14]}$ For instance, hydrolysis of diethyl 4nitrophenylthiophosphate (parathion) at $\mathrm{pH}=8.5$ was extremely slow. However, addition of a catalytic amount of these metallacycles enhanced notably the hydrolysis rate. Recently, a palladium thiophosphate compound 21 (Scheme 39) obtained by reaction of $\mathbf{1 7}$ with methylparathion, has been isolated and characterized demonstrating that such complexes are possible intermediates in the catalyzed hydrolysis of methylparathion. ${ }^{[115]}$ A plausible mechanism for the hydrolysis of thiophosphoric acid esters is shown in Scheme 39.<smiles></smiles>

21<smiles>[X][M]c1cc([R])ccc1/C(C)=N/O</smiles><smiles>OCCO</smiles><smiles>[X][M]1[X]c2cc([R])ccc2C(C)=[N+]1[O-]</smiles><smiles>[Z][M]C1CCOP(=S)(OCC)ON=C1c1ccc([R])cc1[Z]</smiles>

Scheme 39. Proposed mechanism for the hydrolysis of thiophosphates.

New palladacycles immobilized on silica gel 22 and 23 (Figure 4) proved to be reusable in ten runs during the methanolysis of a series of thiophosphate pesticides up to $4.9 \times 10^{8}$ folds at $\mathrm{pH}=8.8$ at $25^{\circ} \mathrm{C} \cdot{ }^{[116]}$ 
<smiles>Cc1c2ccc(OC(=O)NCCC[Si]3(O)OC4CCCCCCC(C4)O3)cc2[p+](O)n1O</smiles>

22<smiles></smiles>

23

Figure 4. Silica gel supported palladacyles for thiophosphate hydrolysis.

\section{Other Applications}

Direct arylation of benzothiazole with aryl iodides and bromides has been achieved under phosphine-free conditions by employing the oxime palladacycle 1e (Figure 1) as precatalyst. ${ }^{[17]}$ The reaction takes place in DMA at $140{ }^{\circ} \mathrm{C}$ with $\mathrm{K}_{2} \mathrm{CO}_{3}$ as base in variable yields (Scheme $40 \mathrm{a}$ ). The intermolecular arylation of 2-halogen substituted benzamides allows the synthesis of benzo[c]phenanthridine alkaloids (Scheme 40b).

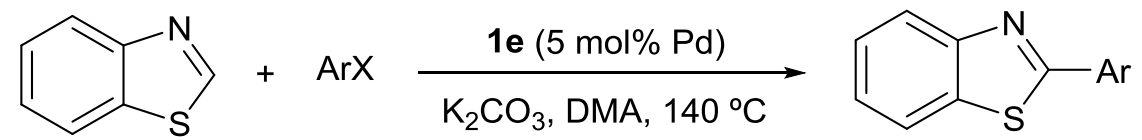

$(30-90 \%)$<smiles>[R]c1ccc(N(C)C(=O)c2ccccc2[X])cc1</smiles><smiles>CC(C)(C)O[Mg]</smiles>

$[\mathrm{X}=\mathrm{I}, \mathrm{Br}, \mathrm{Cl}]$<smiles>[R]c1cccc2c1C=CC=C1C=C2N(C)C1=O</smiles>

$(18-97 \%)$

Scheme 40. Direct arylation of benzothiazole and 2-haloamides.

4-Hydroxyacetophenone oxime palladacycle 1e $(5 \mathrm{~mol} \% \mathrm{Pd})$ has demonstrated catalytic activity in the rearrangement of aldoximes to amides and in the dehydration to nitriles (Scheme 41). ${ }^{[118]}$ These processes are carried out under water reflux and in acetonitrile, respectively with slightly lower yields than with complex 24 (Scheme 41). 


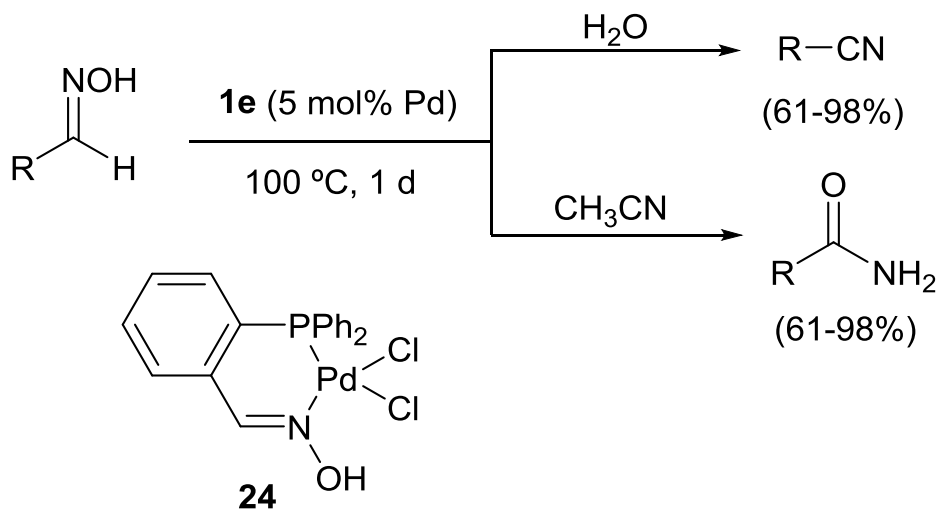

Scheme 41. Rearrangement and dehydratation of aldoximes.

\section{Conclusions}

Oxime-derived palladacycles are robust complex easily accessible from oximes, which in solution suffer easily reductive elimination promoted by water, alcohols and amines to give 3 and 4 atom Pd clusters as has been recently found, which are the real catalysts in cross-coupling and alkynyation reactions. Their catalytic activity has been compared with other Pd salts or complexes showing in general a higher efficiency. Recycling experiments of the active $\mathrm{Pd}$ species in the solution can be performed. The accessibility of aromatic carbonyl compounds allows an easy design of supported complexes to different organic and inorganic supports, especially silica gel and fluorinated tags, allowing the recovery of the unreacted complex and very low leaching in some selected cases. Concerning the reaction conditions, either organic or aqueous solvents can be used under relative low Pd loading. In general, it is possible to work under ligand free conditions by activation of aryl iodides, bromides and even chlorides as well as sulfonates. Only with very challenging aryl chlorides it is necessary the addition of phosphine as ligands. These palladacycles can be not only used in classical cross-coupling reactions but also in ketones arylation, carbonylation, C-H activation, aldoximes rearrangements and several annulations, such as cyclization with ortho-halogen substituted compounds and internal alkynes, oxyarylation of alkenes and Pauson-Khand reaction. Specially interesting and unique catalytic activity of these type of palladacycles as metallohydrolases allows the easy hydrolysis of carboxylic and phosphoric acid esters as well as thiophosphate pesticides.

\section{Acknowledgements}

The Spanish Ministerio de Ciencia e Innovación (MICINN) (projects BQ2001-0724, CTQ2004-00808, CTQ 200762771/BQU, Consolider Ingenio 2010, CSD2007-00006, CTQ2010-20387), Spanish Ministerio de Economia y Competitividad (MINECO) (projects CTQ2013-43446-P and CTQ2014-51912-REDC), FEDER, the Generalitat Valenciana (PROMETEO 2009/039 and PROMETEOII/2014/017) and the University of Alicante are gratefully acknowledged for financial support. I would like to thank to all my collaborators for their participation and generous work over the years.

\section{Keywords: Cross-coupling reactions $•$ Palladiumcatalysis $•$ Annulations $\bullet W a t e r \cdot N a n o p a r t i c l e s$}

[1] R. B. Bedford, Chem. Commun.2003, 1787-1796.

[2] I. P. Beletskaya, A. V. Cheprakov, J. Organomet. Chem. 2004, 689, 4055-4082.

[3] Palladacycles: Synthesis, Characterization and Applications (Ed.: J. Dupont, M. Pfeifer), Wiley-VCH Verlag, Weinheim, 2008.

[4] J. Dupont, C. S. Consorti, J. Spencer, Chem. Rev. 2005, 105, 2529-2571.

[5] R. Ratti, Can. Chem. Trans. 2014, 2, 467-488.

[6] A. C. Cope, R. W. Siekman, J. Am. Chem. Soc. 1965, 87, 3272-3273.

[7] W. A. Herrmann, C. Brosnsmer, K. Ofele, C.-P. Reisinger, T. Priermeier, M. Beller, H. Fischer, Angew. Chem., Int. Ed. Engl. 1995, 34, 1844-1848.

[8] H. Onoue, K. Minami, K. Nakagawa, Bull. Chem. Soc. Jpn. 1970, 43, 3480-3485. 
[9] D. A. Alonso, L. Botella, C. Nájera, M. C. Pacheco, Synthesis 2004, 1713-1718.

[10] E. Alacid, D. A. Alonso, L. Botella, C.Nájera, M. C. Pacheco, Chem. Rec. 2006, 6, 117-132.

[11] D. A. Alonso, C. Nájera, Chem. Soc. Rev. 2010, 39, 2891-2902.

[12] M. C. Pacheco, PhD Thesis, University of Alicante, Alicante 2003.

[13] E. Alacid, C.Nájera, Synlett 2006, 2959-2964.

[14] E. Alacid, C.Nájera, J. Organomet. Chem. 2009, 694, 1658-1665.

[15] A. Leyva-Pérez, J. Oliver-Messeguer, P. Rubio-Marqués, A. Corma, Angew. Chem. Int. Ed. 2013, 52, 1155411559 .

[16] N. Marion, S. P. Nolan, Acc. Chem. Res. 2008, 41, 1440-1449.

[17] R. W. Y. Mann, A. R.C. Brown, M. O. Wolf, Angew. Chem. Int. Ed. 2012, 51, 11350-11353.

[18] D. A. Alonso, C. Nájera, M. C. Pacheco, Org. Lett. 2000, 2, 1823-1826.

[19] D. A. Alonso, C. Nájera, M. C. Pacheco, Adv. Synth. Catal. 2002, 344, 172-183.

[20] X.-P. Cao, D. Barth, D. Kuck, Eur. J. Org. Chem. 2005, 3482-3488.

[21] S. Iyer, C. Ramesh, Tetrahedron Lett. 2000, 41, 8981-8984.

[22] S. Iyer, A. Jayanthi, Tetrahedron Lett. 2001, 42, 7877-7878.

[23] S. Iyer, A. Jayanthi, Synlett 2003, 1125-1128.

[24] S. Iyer, G. M. Kulkarni, C. Ramesh, Tetrahedron 2004, 60, 2163-2172.

[25] S. lyer, G. M. Kulkarni, C. Ramesh, A. K. Saltar, Ind. J. Chem. 2005, 44B, 1894-1908

[26] I. P. Beletskaya, A. N. Kashin, N. B. Karlstedt, A. V. Mitin, A. V. Cheprakov, G. M. Kazankov, J. Organomet. Chem. 2001, 622, 89-96.

[27] L. Botella, C. Nájera, Tetrahedron 2004, 60, 5563-5570.

[28] S. Kim, H. Ko, J. E. Park, S. Jung, S. K. Lee, Y.-J. Chun, J. Med. Chem. 2002, 45, 160-164.

[29] L. Botella, C. Nájera, Tetrahedron Lett. 2004, 45, 1833-1836.

[30] L. Botella, C. Nájera, J. Org. Chem. 2005, 70, 4360-4369.

[31] C.Baleizão, A. Corma, H. García, A. Leyva, Chem. Commun. 2003, 606-607.

[32] A. Corma, H. García, A. Leyva, Tetrahedron 2004, 60, 8553-8560.

[33] E. Alacid, C. Nájera, ARKIVOC 2008, viii, 50-67.

[34] K. Mennecke, W. Solodenko, A. Kirschning, Synthesis 2008, 1589-1599.

[35] J. J. Tindale, P. J. Ragogna, Can. J. Chem. 2010, 88, 27-34.

[36] T. C. Zebovitz, R. F. Heck, J. Org. Chem. 1977, 42, 3907-3909.

[37] G. Battistuzzi, S. Cacchi, G. Fabrizi, Org. Lett. 2003, 5, 777-780.

[38] G. Battistuzzi, S. Cacchi, G. Fabrizi, R. Bernini, Synlett 2003, 1133-1136.

[39] See, references in: C. Nájera, L. Botella, Tetrahedron 2005, 61, 9688-9695.

[40] E. Alacid, C. Nájera, Eur. J. Org. Chem. 2008, 3102-3106; Synfacts 2008, 9, 1008.

[41] W. Susanto, C.-Y.Chu, W. J. Ang, T.-C.Chou, L.-C. Lo, Y. Lam, Green Chem. 2012, 14, 77-80.

[42] W. Susanto, C.-Y.Chu, W. J. Ang, T.-C.Chou, L.-C. Lo, Y. Lam, J. Org. Chem. 2012, 77, 2729-2742.

[43] For a review, see: J. Muzart, Tetrahedron 2005, 61, 4179-4212.

[44] V. Caló, A. Nacci, A. Monopoli, V. Ferola, J. Org. Chem. 2007, 72, 2596-2601.

[45] J. Mo, L. Xu, J. Ruan, S. Liu, J. Xiao, Chem. Commun. 2006, 3591-3593.

[46] F. Berthiol, H. Doucet, M. Santelli, Tetrahedron Lett. 2004, 45, 5633-5636.

[47] W. Cabri, I. Candiani, Acc. Chem. Res. 1995, 28, 2-7.

[48] E. Alacid, C. Nájera, Adv. Synth. Catal. 2007, 349, 2572-2584.

[49] C. B. Ziegler Jr., R. F. Heck, J. Org. Chem. 1978, 43, 2949-2952.

[50] E. Alacid, C. Nájera, Adv. Synth.Catal.2008, 350, 1316-1322.

[51] R. V. Pirovani, B. R. V. Ferreira, F. Coelho, Synlett 2009, 2333-2337.

[52] B. R. V. Ferreira, R. V. Pirovani, L. G. Souza-Filho, F. Coelho, Tetrahedron 2009, 65, 7712-7717

[53] K. R. de Luna Freire, C. F. Tormena, F. Coelho, Synlett, 2011, 2059-2063.

[54] J. E. Plevyak, R. F. Heck, J. Org. Chem. 1978, 43, 2454-2456.

[55] C. R. Smith, T. V. RajanBabu, Tetrahedron 2010, 66, 1102-1110.

[56] G. Arena, E. Cini, E. Petricci, R. Randino, M. Taddei, Org. Chem. Front. 2015, 2, 526-530.

[57] K. Kikukawa, T. Matsuda, Chem. Lett. 1977, 159-162.

[58] A. Roglans, A. Pla-Quintana, M. Moreno-Mañas, Chem. Rev. 2006, 106, 4622-4643.

[59] J. G. Taylor, A. V. Mora, C. R. D. Correia, Eur. J. Org. Chem. 2011, 1403-1428.

[60] F.-X. Felpin, L. Nassar-Hardy, F. Le Callonnec, E. Fouquet, Tetrahedron 2011, 67, 2815-2831.

[61] J. Salabert, R. M. Sebastián, A. Vallribera, A. Roglans, C. Nájera, Tetrahedron 2011, 67, 8659-8664.

[62] J. Salabert, R. M. Sebastián, A. Vallribera, J. F. Cívicos, C. Nájera, Tetrahedron 2013, 69, 2655-2659.

163] D. A. Alonso, C. Nájera, M. C. Pacheco, J. Org. Chem. 2002, 67, 5588-5594.

[64] A. Costa, C. Nájera, J. M. Sansano, J. Org. Chem. 2002, 67, 5216-5225.

[65] L. Botella, C. Nájera, Angew. Chem. Int. Ed. 2002, 41, 179-181.

[66] L. Botella, C. Nájera, J. Organomet. Chem. 2002, 663, 46-57.

[67] R. Ortiz, M. Yus, Tetrahedron 2005, 61, 1699-1707.

[68] A. Corma, H. García, A. Leyva, Tetrahedron 2005, 61, 9848-9854.

[69] E. Alacid, C. Nájera, Org. Lett. 2008, 10, 5011-5014; Synfacts 2009, 2, 0197.

[70] E. Alacid, C. Nájera, J. Org. Chem. 2009, 74, 2321-2327.

[71] E. Alacid, C. Nájera, J. Org. Chem. 2009, 74, 8191-8195.

[72] D. A. Alonso, J. F. Cívicos, C. Nájera, Synlett 2009, 3011-3015

[73] D. A. Alonso, J. F. Cívicos, C. Nájera, Adv. Synth.Catal. 2011, 353, 1683-1687.

[74] E. P. Gillis, M. D. Burke, Aldrichimica Acta 2009, 42,17-27.

[75] G. Zeni, R. C. Larock, Chem. Rev. 2006, 106, 4644-4680.

[76] D.-G. Yu, B.-J.Li, Z.-J. Shi, Acc. Chem. Res. 2010, 43, 1486-1495.

[77] B.-J. Li, D.-J.Yu, C.-L.Sun, Z.-J. Shi, Chem. Eur. J. 2011, 17, 1728-1759.

[78] J. F. Cívicos, M. Gholinejad, D. A. Alonso, C. Nájera, Chem. Lett. 2011,40, 907-909.

[79] J. F. Cívicos, D. A. Alonso, C. Nájera, Eur. J. Org. Chem.2012, 3670-3676.

[80] J. F. Cívicos, D. A. Alonso, C. Nájera, Adv. Synth. Catal. 2012,354, 2771-2776.

[81] C.Baleizão, A. Corma, H. García, A. Leyva, J. Org. Chem. 2004, 69, 432-446.

[82] A. Corma, D. Das, H. García, A. Leyva, J. Catal. 2005, 29, 322-331. 
[83] W. Solodenko, C. Brochwitz, R. Wartchow, M. A. Hashem. K. M. Dawood, M. Vaultier, A. Kirschning, Mol. Div. 2005, 9, 333-339.

[84] W. Solodenko, K. Mennecke, C. Vogt, S. Gruhl, A. Kirschning, Synthesis 2006, 1873-1881.

[85] Q.-P. Liu, Y.-C. Chen, Y. Wu, J. Zhu, J.-G. Deng, Synlett 2006, 1503-1506.

[86] E. Alacid, C. Nájera, J. Organomet. Chem. 2009, 694, 1658-1665.

[87] H.-J. Cho, S. Jung, S. Kong, S.-J. Park, S.-M. Lee, Y.-S. Lee, Adv. Synth. Catal. 2014, 356, 1056-1064

[88] Y.-C. Yang, P. H. Toy, Synlett 2014, 25, 1319-1324.

[89] M. Gholinejad, M. Razeghi, C. Nájera, RSC Adv. 2015, 5, 49568-49576.

[90] E. Alacid, C. Nájera, Adv. Synth. Catal. 2006, 348, 945-952.

[91] E. Alacid, C. Nájera, Adv. Synth. Catal. 2006, 348, 2085-2091.

[92] E. Alacid, C. Nájera, J. Org. Chem. 2008, 73, 2315-2322.

[93] F.-T. Luo, A. Jeevanadam, M. K. Basu, Tetrahedron Lett. 1998, 39, 7939-7942.

[94] D. A. Alonso, C. Nájera, M. C. Pacheco, Tetrahedron Lett. 2002, 43, 9365-9368.

[95] D. A. Alonso, C. Nájera, M. C. Pacheco, Adv. Synth. Catal. 2003, 345, 1146-1158.

[96] J. F. Cívicos, D. A. Alonso, C. Nájera, Adv. Synth. Catal. 2013, 355, 203-208.

[97] E. Buxaderas, D. A. Alonso, C. Nájera, Eur. J. Org. Chem.2013, 5864-5870.

[98] E. Buxaderas, D. A. Alonso, C. Nájera, Adv. Synth. Catal. 2014, 356, 3415-3421.

[99] E. Buxaderas, D. A. Alonso, C. Nájera, RSC Adv. 2014, 4, 46508-46512.

[100] C. Zhaler, O. V. Zatolochnaga, N. V. Zvyagintsev, V. A. Ananikov, V. Gevorgyan, Org. Lett. 2012, 14, 28462849.

[101] D. A. Alonso, C. Nájera, M. C. Pacheco, J. Org. Chem. 2004, 69, 1615-1619.

[102] W. J. Ang, L.-C. Lo, Y. Lam, Tetrahedron 2014, 70, 8545-8558.

[103] R. C. Larock, M. J. Doty, J. Org. Chem. 1993, 58, 4579-4583.

[104] R. C. Larock, E. K. Yum, M. D. Refvik, J. Org. Chem. 1998, 63, 7652-7662.

[105] W. J. Ang, C.-H. Tai, L.-C. Lo, Y. Lam, RSC Adv. 2014, 4, 4921-4929.

[106] L. A. Zeoly, R. C. Barcelos, M. T. Rodríguez Jr., R. C. Gomes, F. Coelho, Tetrahedron Lett. 2015, 56, 28712874.

[107] R. A. C. Leão, V. D. Pinho, A. S. Coelho, C. D. Buarque, P. F. Moraes, D. A. Alonso, C. Nájera, P. R. R. Costa, Eur. J. Org. Chem. 2011, 3313-3316.

[108] P. F. Moraes, F. V. Gaspar, R. H. F. Borges, C. D. Netto, R. A. C. Leão, C. Nájera, P. R. R. Costa, Synthesis 2015, 47, 3505-3512.

[109] T. A. Fernandes, J. L. O. Domingos, L. I. A. da Rocha, S. de Medeiros, C. Nájera, P. R. R. Costa, Eur. J. Org. Chem.2014, 1314-1320.

[110] X.-R. Wang, F.-H. Lu, Y. Song, Z.-L. Lu, Tetrahedron Lett. 2012, 53, 589-592.

[111] Y. Lan, L. Deng, J. Liu, C. Wang, O. Wiest, Z. Yang, Y.-D. Wu, J. Org. Chem. 2009, 74, 5049-5058.

[112] A. K. Yatsimirsky, G. M. Kazankov, A. D. Ryabov, J. Chem. Soc., Perkin Trans. 2 1992, 1295-1300.

[113] E. Y. Bezsoudnova, A. D. Ryabov, J. Organomet. Chem. 2001, 622, 38-42.

[114] G. M. Kazankov, V. S. Sergeeva, E. N. Efremenko, L. Alexandrova, S. D. Varfolomeev, A. D. Ryabov, Angew. Chem. Int. Ed. 2000, 39, 3117-3119.

[115] M. Kim, F. P. Gabbai, Dalton Trans. 2004, 3403-3407.

[116] F.-H. Lu, R. Yue, X.-R. Wang, Z.-L. Lu, Inorg. Chem. Commun. 2013, 34, 19-22.

[117] G. Zhang, X. Zhao, Y. Yan, C. Ding, Eur. J. Org. Chem. 2012, 669-672.

[118] L. Menéndez-Rodríguez, E. Tomás-Mendivil, J. Francos, C. Nájera, P. Crochet, V. Cadierno, Catal. Sci. Technol. 2015, 5, 3754-3761. 


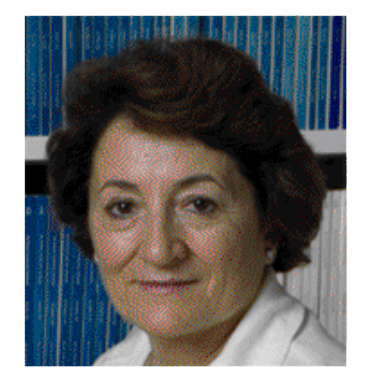

Carmen Nájera was born in Nájera (La Rioja) and was graduated from the University of Zaragoza in 1973, obtaining her doctorate in chemistry from the University of Oviedo in 1979. She spent postdoctoral stays at the ETH (Zurich), the Dyson Perrins Laboratory (Oxford), Harvard University, and Uppsala University. She became Associate Professor in 1985 at the University of Oviedo and Full Professor in 1993 at the University of Alicante. She is coauthor of more than 350 papers and book chapters and has supervised more than 40 PhD students. She has been awarded with the 2006 Organic Chemistry Prize from the Spanish Royal Chemical Society of Chemistry, the 2006 Rosalind Franklin International Lectureship from the English Royal Society, the SCF 2010 French-Spanish Prize from the Société Chimique de France and the IUPAC 2015 Distinguished Women in Chemistry or Chemical Engineering Award. In 2012 she was named full Member of the Royal Spanish Academy of Sciences, and was appointed as Active Member of the European Academy of Sciences and Arts. 
Entry for the Table of Contents (Please choose one layout only)

Layout 1:15 Years of catalysis

\section{FULL PAPER}

15 Years of catalysis: This minireview highlights the catalytic activity of oxime-derived palladacycles for alkenylation, cross-coupling, alkynylation, carbonylation, annulation, $\alpha$-arylation, $\mathrm{C}-\mathrm{H}$ activation, oxime rearrangement reactions and as metalloenzymes in hydrolytic processes among others applications in organic synthesis

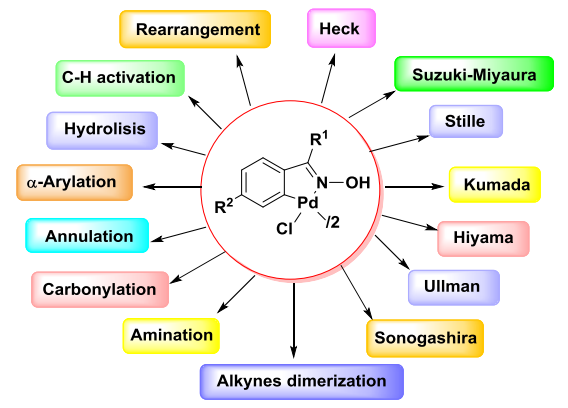

Carmen Nájera

Page No. - Page No.

Oxime-derived Palladacycles: Applications in Catalysis 